\title{
Painting the Palace of Apries Il: ancient pigments of the reliefs from the Palace of Apries, Lower Egypt
}

Signe Buccarella Hedegaard ${ }^{1}$, Thomas Delbey ${ }^{2}$, Cecilie Brøns ${ }^{1}$ and Kaare Lund Rasmussen²*0

\begin{abstract}
Fragments of painted limestone reliefs from the Palace of Apries in Upper Egypt excavated by Flinders Petrie in 1908-1910 have been investigated using visible-induced luminescence imaging, micro X-ray fluorescence, laser ablation inductively coupled plasma mass spectrometry, micro X-ray powder diffraction, and Fourier transform infrared spectrometry. The pigments have been mapped, and the use and previous reports of use of pigments are discussed. Mainly lead-antimonate yellow, lead-tin yellow, orpiment, atacamite, gypsum/anhydrite, and Egyptian blue have been detected. It is the first time that lead-antimonate yellow and lead-tin yellow have been identified in ancient Egyptian painting. In fact, this is the earliest examples known of both of these yellow pigments in the world.
\end{abstract}

Keywords: Ancient Egyptian polychromy, Apries Palace, $\mu$-XRF, LA-ICP-MS, $\mu$-XRPD, FTIR, VIL, Lead-antimonate yellow, Lead-tin yellow, Orpiment, Atacamite, Egyptian blue

\section{Introduction}

This paper constitutes the second and final article in the series on the technical examination of the painted fragments from the so-called Palace of Apries housed in the collection of the Ny Carlsberg Glyptotek (NCG). Whereas the first article focuses on the organic components [1], this article deals with the pigments used.

Although the number of technical studies of ancient Egyptian painting is increasing, it is still infinitesimal considering that it pertains to a period spanning thousands of years. The majority of the published studies focus on material from the New Kingdom [2-5] and the Greco-Roman Period [6]. ${ }^{1}$ Thus, our knowledge is quite limited concerning painting and pigments from the intervening seven centuries generally referred to as the Third Intermediate Period (c. 1070-664 BCE) and the Late Period (c. 664-332 BCE). Furthermore, most of the studies published from these less elucidated periods focus on coffins and papyri rather than wall paintings. Moreover,

\footnotetext{
*Correspondence: klr@sdu.dk

${ }^{2}$ CHART, Institute of Physics, Chemistry and Pharmacy, University of Southern Denmark, Odense, Denmark

Full list of author information is available at the end of the article
}

the published investigations of wall paintings throughout ancient Egyptian history, almost exclusively cover examples from temples, tomb-chapels, and burial chambers. Thus, the investigation of the Palace of Apries constitutes a significant contribution to our understanding of painted decoration from the Late Period as well as to our knowledge of wall paintings in relation to secular prestige buildings.

Although pigments are generally inorganic, a few dyebased pigments were in use in antiquity. These include semi-organic pigments, such as lakes based on madder (multiple dyestuffs incl. $\mathrm{C}_{14} \mathrm{H}_{8} \mathrm{O}_{4}$ and $\mathrm{C}_{15} \mathrm{H}_{8} \mathrm{O}_{7}$ ), and organic pigments, such as indigo $\left(\mathrm{C}_{16} \mathrm{H}_{10} \mathrm{~N}_{2} \mathrm{O}_{2}\right)$. Many organic pigments can be detected by gas chromatography mass spectrometry (GC-MS) - a technique which has been applied to the samples in the first paper of this sequel [1]. The GC-MS data did not reveal the presence of any organic pigments. In the present work, the

\footnotetext{
1 The APPEAR (Ancient Panel Paintings: Examination, Analysis, and Research) Project investigates mummy portraits from Roman-era Egypt. Technical information is gathered from multiple collections worldwide and made available through an online database. See: http://www.getty.edu/museu $\mathrm{m} /$ research/appear_project/.
} 
chemical composition of the inorganic pigments is investigated. In order to keep sampling to a minimum, the investigation is largely based on non-invasive measures incl. microscopy, photographic techniques, and micro$\mathrm{X}$-ray fluorescence spectroscopy $(\mu-\mathrm{XRF})$. Laser ablation inductively coupled plasma mass spectrometry (LA-ICP$\mathrm{MS})$, micro-X-ray powder diffraction ( $\mu$-XRPD), and Fourier transform infrared spectrometry (FTIR) have been carried out, on single samples, in order to resolve compositional complexities.

Considering that the fragments have lain buried in the ground for millennia, the inorganic pigments identified in this study have undergone very little degradation. It could, however, be speculated that organic colorants might have been present, but have now been lost due to degradation. Although this is theoretically possible from a chemical point of view, there are no indications in the art historical context or from visual appearance of the architectural fragments that a colourant is missing. In fact, the polychromy is so well-preserved that GC-MS analyses have yielded detailed information on the organic components used as binders and coatings [1].

\section{Ancient Egyptian pigments: a review}

Comparative studies are made difficult by the lack of relevant pigment studies from the Third Intermediate Period and the Late Period. The few published studies focusing on pigments from the said periods typically treat of artefacts such as papyri and coffins which differ significantly in size, function, and materials-and therefore in painting techniques and pigment palettes. For this reason a review of the pigments thus far attested on artefacts contemporary to the Palace of Apries would not be meaningful in this context. Albeit our current knowledge of ancient Egyptian wall painting is based on architectural structures predating the fragments examined in this study, this knowledge is deemed more relevant for the assessment of the palette used for wall decorations in the Third Intermediate Period and the Late Period. Thus, due to lack of information on contemporary wall painting, the pigments so far identified in ancient Egyptian painting, up to and including the Late Period, are included in the present review.

\section{White pigments}

Calcite $\left(\mathrm{CaCO}_{3}\right)$, gypsum $\left(\mathrm{CaSO}_{4} \cdot 2 \mathrm{H}_{2} \mathrm{O}\right)$ and anhydrite $\left(\mathrm{CaSO}_{4}\right)$ are the most common pigments in painted decoration in ancient Egypt from the Predynastic Period through the Roman Period. First and foremost, these white pigments were used for the ground layer often serving as the preparatory layer as well as the background colour. In addition, they were used for the paint layers applied on top of the ground layer. Calcite and natural calcium sulphates are widely available in Egypt $[3,4,6]$. When heated to c. $90{ }^{\circ} \mathrm{C}$, gypsum converts to hemihydrate $\left(2 \mathrm{CaSO}_{4} \cdot 2 \mathrm{H}_{2} \mathrm{O}\right)$, whereas it is converted to anhydrite when heated to $200{ }^{\circ} \mathrm{C}$. The fact that these dehydrated phases are sometimes found in ancient Egyptian ground layers indicates that the gypsum has been heated. However, since mixtures of anhydrite and gypsum occur in natural deposits [6,7], the dehydrated phases may have formed as a result of anthropogenic intervention or geological processes.

Furthermore, the magnesium calcium carbonate mineral huntite $\left(\mathrm{Mg}_{3} \mathrm{Ca}\left(\mathrm{CO}_{3}\right)_{4}\right)$ has also been attested in several cases dating from the Old Kingdom onwards. Huntite is an outstanding painting material which provides a brighter white than calcite and ensures a smooth painted surface due to its adhesiveness and small particle size. Although used less extensively than the other white pigments, recent studies suggest that the use of huntite was more wide-spread than previously thought. In fact, it appears to have been the predominant white pigment during the New Kingdom (18th, 19th and 20th Dynasties) $[3,7]$. Huntite is structurally and chemically similar to calcite, magnesite $\left(\mathrm{MgCO}_{3}\right)$ and dolomite $([\mathrm{Ca}, \mathrm{Mg}]$ $\left.\left[\mathrm{CO}_{3}\right]_{2}\right)$. It occurs as soft, white, fine-grained, compact and porous masses which crumble easily. Huntite typically forms as an alteration product of dolomite- and magnesite-bearing rocks. It can also form via precipitation in vugs, caves, and fault zones [8].

\section{Blue pigments}

The principal blue pigment employed in ancient Egypt is the synthetic pigment today known as Egyptian blue. Whether invented in Mesopotamia or Egypt, the pigment was evidently in use in Egypt from the early 3rd millennium $\mathrm{BCE}[8,9]$. Manufacture seems to have quickly gained momentum from that time and archaeological evidence supports the hypothesis that the production of Egyptian blue continued in Egypt until at least the third century CE $[3,10]$. The pigment is prepared from a mixture of quartz, lime, a copper compound, and an alkali flux which is fired at temperatures around 850 to $1000{ }^{\circ} \mathrm{C}$. The principal components of Egyptian blue are blue calcium-copper tetrasilicate crystals [synthesised cuprorivaite $\left.\left(\mathrm{CaCuSi}_{4} \mathrm{O}_{10}\right)\right]$ and partially reacted quartz particles bonded together by a glass phase [9].

Widely recorded in painted archaeological materials, Egyptian blue was clearly in routine use as a standard blue pigment of Egyptian art [4, 8]. In fact, other blue pigments account for a miniscule proportion of the countless examples of blue in ancient Egyptian polychromy. Thus, azurite $\left(\mathrm{Cu}_{3}\left(\mathrm{CO}_{3}\right)_{2}(\mathrm{OH})_{2}\right)$, a natural bright blue carbonate of copper which was widely used from Antiquity until the end of the seventeenth century [8], occurs 
extremely rarely in Egyptian contexts [4]. In fact, the only confirmed example is a fragment of painted leather from the Asaif Valley at Thebes. The leather fragment is stylistically dated to the early 18th Dynasty, specifically between the reign of Ahmose I and the joint reign of Hatshepsut and Thutmose III (c. 1550-1458 BCE) [11]. Likewise, the only confirmed attestation of the deep blue mineral lapis lazuli in ancient Egypt is a fragmented statue of a queen also found at the Asaif Vally and stylistically dated to the late 17th Dynasty (1585-1549 BCE) [11]. Exclusively sourced from the Sar-i-Sang mines in the Badakhshan region of northern Afghanistan, lapis lazuli was incredibly expensive and ancient examples of it used as a pigment are extremely rare [12, 13].

It would appear that the only other blue pigment used to an appreciable extend in ancient Egypt was a cobaltbased pigment known as Amarna blue $\left(\mathrm{CoO} \cdot \mathrm{Al}_{2} \mathrm{O}_{3}\right)$. This pigment has exclusively been attested on pottery from the Amarna period (c. 1365-1345 BCE) [4, 14].

\section{Green pigments}

For green, the ancient Egyptians generally used a synthetic pigment which has since become known as Egyptian green. This pigment is produced by varying the ratios of the starting components and the formation conditions used in the production of Egyptian blue. Thus, producing Egyptian green requires more silica $[4,8]$ and lime and less copper [8] than the blue variant. Furthermore, the melt must be heated to temperatures around 950$1100{ }^{\circ} \mathrm{C}$ in a reducing atmosphere. Two types of Egyptian green have been identified: a glass-rich pigment with cuprowollastonite $\left((\mathrm{Ca}, \mathrm{Cu})_{3}\left(\mathrm{Si}_{3} \mathrm{O}_{9}\right)\right)$ as a minor phase and a cuprowollastonite-rich pigment with glass and silica as minor phases [8]. The earliest known example of Egyptian green is nearly a millennium younger than the earliest known example of Egyptian blue [15].

In addition to Egyptian green a few other green pigments have been identified in ancient Egyptian contexts. These include chrysocolla $\left(\mathrm{CuSiO}_{3} \cdot 2 \mathrm{H}_{2} \mathrm{O}\right)$ and malachite $\left(\mathrm{Cu}_{2}\left(\mathrm{CO}_{3}\right)(\mathrm{OH})_{2}\right)$ which both form as secondary minerals in the upper oxidizing zones of copper ore deposits. The two green minerals occur together along with many other minerals including azurite [8]. The few examples of chrysocolla known include pigment samples from eleventh-century wall decorations at Thebes [14] and the 18th-Dynasty Workmen's Village at Amarna [16]. Malachite has recently been attested in several instances suggesting that this pigment was more widely used than hitherto recognised. Thus, numerous examples of malachite have been found in wall paintings as well as on stone and wooden artefacts dated to the Old Kingdom onwards $[15,17]$. The examples include several coffins dated to the 26th Dynasty [18].
Furthermore, green copper chlorides such as atacamite $\left(\mathrm{Cu}_{2} \mathrm{Cl}(\mathrm{OH})_{3}\right)$ and other mineral species in the atacamite family have been identified in green pigments from the 5 th Dynasty onwards $[2,4,14,15]$. In nature, these copper chlorides form in the weathering zone around copper lode deposits, particularly when the erosion occurs in a desert environment. However, atacamite and other copper chlorides can also be produced artificially. The relative rarity of naturally forming copper chlorides $[8$, 14] combined with the compositional chemistry and complexity of the copper chlorides identified in painted decorations from ancient Egypt point to artificial pigment production [2]. It is not clear exactly how these pigments were made in ancient Egypt. However, Medieval recipes for preparing green copper pigments using common salt, which are known to produce malachite and atacamite, might hint at the preparation technique(s) used. According to Theophilus' (c. twelfth century) recipe, viride salsum, literally, 'salt green', was produced by covering copper in honey and salt and exposing it to urine and vinegar vapours $[8,19]$.

However, this origin of both copper chlorides and malachite has been disputed and several studies have emphasized the different degradation processes, which can lead to the formation of the two mineral phases. Even if azurite seems to be very rarely used as a pigment in ancient Egypt, it should be noted that its degradation can produce malachite in humid and alkaline environments [20, 21]. Atacamite and its polymorphs can originate from the weathering of several $\mathrm{Cu}$-bearing pigments such as cuprorivaite [22-25], azurite [20, 21, 26-28] and malachite [28-30] depending on the $\mathrm{pH}$ and the presence of $\mathrm{Cl}^{-}$ions. Leached $\mathrm{Cu}^{2+}$ ions could react with chlorinerich solutions forming copper chloride. The observation of several painted fragments from ancient Egypt suggests that malachite and the copper chlorides could also be the product of the preparation of Egyptian green forming after the decomposition of the crushed copper-rich glaze [23].

\section{Red pigments}

Red ochre was the predominant red pigment throughout the history of ancient Egypt. Red ochre is often referred to as the naturally occurring iron(III) oxide hematite $\left(\alpha-\mathrm{Fe}_{2} \mathrm{O}_{3}\right)$, the principal colouring matter in red earth pigments. Besides iron oxides, red earth pigments usually contain other minerals such as quartz and clays. Since iron oxides have high pigmenting power, even very saturated red earth pigments may contain a low concentration of iron minerals compared to the concentration of accessory minerals. Deposits of iron oxides are attested in quantity within Egypt [31]. Red ochres typically form in the oxidised, weathered portions of iron-rich mineral 
deposits, especially where associated with volcanic massive sulphide deposits. Hematite can also be produced artificially by roasting yellow, brown, or red ochres thus converting them into the stable iron(III) oxide [8, 32]. Distinguishing between the natural and the artificial kinds is usually rather difficult unless crystallographic analysis is performed. (Artificially produced versions will often have been heated to temperatures exceeding 800$900{ }^{\circ} \mathrm{C}$ which leaves the crystal structure considerably disordered) [8]. A morphological study has revealed that naturally occurring red ochre has been used for the wall decoration in an 18th Dynasty palace [33].

In addition to red ochre, realgar $\left(\alpha-\mathrm{As}_{4} \mathrm{~S}_{4}\right)$, an orangered arsenic sulphide mineral, has been attested in a few instances, primarily comprising details on papyri and in wall paintings from the 18th and 19th Dynasties [4, 3436]. Besides being highly toxic, realgar is extremely lightsensitive and easily degrades to pararealgar $\left(\gamma-\mathrm{As}_{4} \mathrm{~S}_{4}\right)$ which is orange-yellow. In nature, realgar often occurs in association with other arsenic sulphide minerals such as pararealgar and orpiment $\left(\mathrm{As}_{2} \mathrm{~S}_{3}\right)$ forming massive encrusting or granular deposits. It is primarily found in the oxidised portions of arsenic veins. However, it also occurs in association with cinnabar $(\mathrm{HgS})$ and antimony deposits and as sublimates from volcanoes, particularly from Vesuvius, the Phlegrian Fields around the Bay of Naples, and the Aeolian Islands [8]. Arsenic sulphide minerals are reported to be present in all gold and silver ores, in the copper ore from the Sinai and in galena deposits in the Eastern desert [37]. Thus, it seems the ancient Egyptians could have obtained supplies from multiple sources.

Furthermore, only one example of the red mercury(II) sulphide mineral cinnabar has so far been identified in ancient Egyptian painting: a floral element decorating a 26th-Dynasty sarcophagus [38]. Thus, it would appear that cinnabar was used extremely rarely until the late Ptolemaic or early Roman period wherefrom several examples have been attested [6]. ${ }^{2}$ Cinnabar commonly forms in veins and small impregnations associated with volcanic activity and hot springs. The most important European source of cinnabar is Almaden, Spain [8].

\section{Yellow pigments}

Similar to the red pigments, the yellow pigments employed in ancient Egyptian painting are primarily

\footnotetext{
${ }^{2}$ Scott's other example is misrepresented: the pigment has been identified on papyrus (BM EA9916) dated to the late Ptolemaic or early Roman Period-not the Late Period. Also, it would appear that Scott is confusing realgar and cinnabar when stating that the pigment has been in use since the 12th Dynasty: the reference given deals with orpiment and realgar. (In the chapter on vermillion and cinnabar in the same series it is stated that cinnabar was not used in ancient Egypt [39]).
}

based on iron earth pigments with the addition of an arsenic sulphide mineral. Thus, the vast majority of yellow pigments identified in ancient Egyptian contexts are yellow ochres consisting of clays with variable amounts of the iron oxide hydroxide goethite $(\alpha-\mathrm{FeO} \cdot \mathrm{OH})$ and sometimes so-called limonite $\left(\mathrm{FeO} \cdot \mathrm{nH}_{2} \mathrm{O}\right)$ which are poorly crystalline, hydrated oxides of iron [8, 31]. Yellow ochres form either as the direct weathering of iron-rich ore deposits or as soils, concentrating iron for underlying bedrocks. Goethite is the most commonly occurring iron oxide in soils and is found in abundance in localities worldwide including Egypt [8].

The yellow arsenic sulphide mineral orpiment has been identified in several painted decorations from at least the 12th Dynasty onwards [2-4, 31, 40]. Although similarly poisonous and unstable, it would appear to have been used considerably more frequently than its orange-red counterpart realgar. The preference for orpiment was probably due to its bright yellow, glittering appearance reminiscent of gold. Indeed, orpiment was sometimes used in its place [2, 31]. As mentioned, orpiment and realgar occur together along with other arsenic sulphide minerals typically in the oxidised parts of arsenic veins [8]. Apparently, orpiment also occurs in association with cinnabar, antimony, galena, gold, silver, and copper [37].

In addition to yellow ochre and orpiment, examples of the lemon-yellow iron sulphate minerals jarosite $\left(\mathrm{KFe}_{3}\left(\mathrm{SO}_{4}\right)_{2}(\mathrm{OH})_{6}\right)$ and natrojarosite $\left(\mathrm{NaFe}_{3}\left(\mathrm{SO}_{4}\right)_{2}(\mathrm{OH})_{6}\right)$ have been attested in ancient Egyptian polychromy from the Old Kingdom to the Ptolemaic Period [4, 31, 41]. Commonly found together, the two minerals form as alteration products of feldspar group minerals in sulphidic soils, and mine waste deposits under acidic conditions. These iron sulphate minerals are found worldwide but occur in limited quantities [8].

\section{The reliefs from the Palace of Apries}

The economic and political centres of ancient Egypt moved into the Nile Delta during the Third Intermediate and Late Period. However, only a few remains of the architectural buildings have been unearthed so far. One of the rare known examples of preserved architecture from this period in the Nile Delta is the so-called Palace of Apries, located in the north end of the ruins of Memphis in Lower Egypt. The main palace building was excavated by W.M.F. Petrie during two seasons between 1908 and 1910. According to Petrie, the palace was part of an extensive complex, which he called a "camp". It is assumed that the "camp" was once a great palace complex, of which the building called the Palace of Apries was only a small part, although possibly the main one. The palace was built on a $13 \mathrm{~m}$ high mudbrick platform, a feature of many monumental buildings from the Late Period in Egypt (as e.g. 
Deir el-Ballas). The mudbrick walls were lined with limestone slabs on the lower parts and there were limestone pavements, doorways, columns, and stairways. Some of the column capitals recovered from the palace bear the name of King Apries, who was most likely the builder of the complex. Consequently, the building complex should be dated to the 26th Dynasty, to the reign of King Apries, c. 589-568 BCE, or shortly thereafter.

Fragments of limestone reliefs were recovered during the excavations. Many of them were recovered in a secondary context and without any visible traces of polychromy. They belong to seven large reliefs, originally decorating the Great Gate of the palace. The reliefs depict the 30th anniversary of the pharaoh. ${ }^{3}$ One of these seven reliefs (ÆIN 1046) was given to the NCG. In addition, eleven polychrome relief fragments were acquired by the NCG in 1909 directly from W.M.F. Petrie's excavations. Unfortunately, Petrie gave no details as to where in the palace the fragments were found, and their original setting is therefore unknown. It is uncertain if the polychrome reliefs in the NCG belong to a part of the Great Gate (pylon), since the size of the decoration of several of the fragments does not correspond to the remaining decoration of this particular structure-they seem smaller in scale. Yet three of the fragments in the NCG are indeed larger in scale (ÆIN 1048, 1050, and 1060). These three fragments might originally have belonged to wall scenes in the palace depicting the king under a star-filled blue sky (ÆIN 1052 and 1054) [44]. The style and motifs of the remaining fragments also correspond to the decoration of the Great Gate (pylon), which may indicate that they were part of its decoration; but of scenes, which it has been impossible to reconstruct [45]. The fragments must have been in a dry, protected location, since their original polychromy is very well preserved. A column capital (ÆIN 1045) and four relief fragments (ÆIN 1048, ÆIN 1049, ÆIN 1059, and ÆIN 1060) were chosen for examination in this work based on their well-preserved polychromy.

\section{Artefacts}

The fragments selected for analysis comprise a capital (ÆIN 1045) and four wall fragments with carved motifs of two different scales. The smaller scale is represented by ÆIN 1058 and 1059, the larger scale by ÆIN 1048 and 1060.

\section{AEIN 1045 [46]}

ÆIN 1045 constitutes a complete monolith column capital of white limestone in the shape of a rosette of palm

\footnotetext{
${ }^{3}$ Reconstructions were carried out by Flinders Petrie [42] and Kaiser [43]
}

leaves, tied around the upper end of the column shaft. The capital retains an extensive amount of ancient polychromy which seems to consist of two separate paint schemes. The carved palm leaves are painted in different green nuances. Traces of gold leaf are preserved in grooves and dents on the leaves as well as on two of the three bands constituting the base. Traces of blue paint are visible on the lower, middle, and upper bands on the base (Fig. 1a).

\section{AEIN 1048 [47]}

The relief fragment is restored from two pieces. It bears the remains of a monumental inscription. From right to left are hieroglyphs representing a wooden column, an animal skin with a tail, a feather, three vases in a stand, and half a loaf of bread. Together the hieroglyphs form part of the epithets of the sun god Behdeti. Underneath the hieroglyphs is a falcon, which is unrelated to the inscription. The paint is applied on a white layer which constitutes the background colour of the decoration. Preparatory drawing in red is visible around the edges of the relief. The column is brown, the animal skin has a wide band of green dots, the feather is green, the vases and the half loaf are blue. The falcon is painted green with extremely fine, black lines delineating the plumage (Fig. 2a).

\section{AEIN 1058 [48]}

The relief fragment depicts a section of a rectangular frame, called a serekh, in which was written the "Horus name", one of the five names of the Egyptian kings. This type of frame was decorated with the Horus name in the upper part of the frame, while the lower part of the frame was decorated with a pattern, imitating the façade of a palace. This fragment has the remains of the "name field" at the top, of which the greater part has broken off and there is, therefore, no traces of the royal name. Below, there is a piece of a patterned palace façade. The frame is carved in slightly raised relief and painted in bright colours on a layer of white. The "name field" is yellow, whereas the horizontal band of palm leaves below is green and black. Preparatory lines in the form of horizontal red lines are visible in the middle section of the painted decoration. Patches of a similar red colour in the lower part might have been guiding the intricate design in like manner (Fig. 2b).

\section{AEIN 1059 [49]}

The relief fragment bears the remains of an inscription: two fragmented hieroglyphs, originally representing a pair of cow horns and a road with bushes along its sides. These hieroglyphs are the beginning of the name of the jackal god Wepwawet. To the left of the inscription, part 


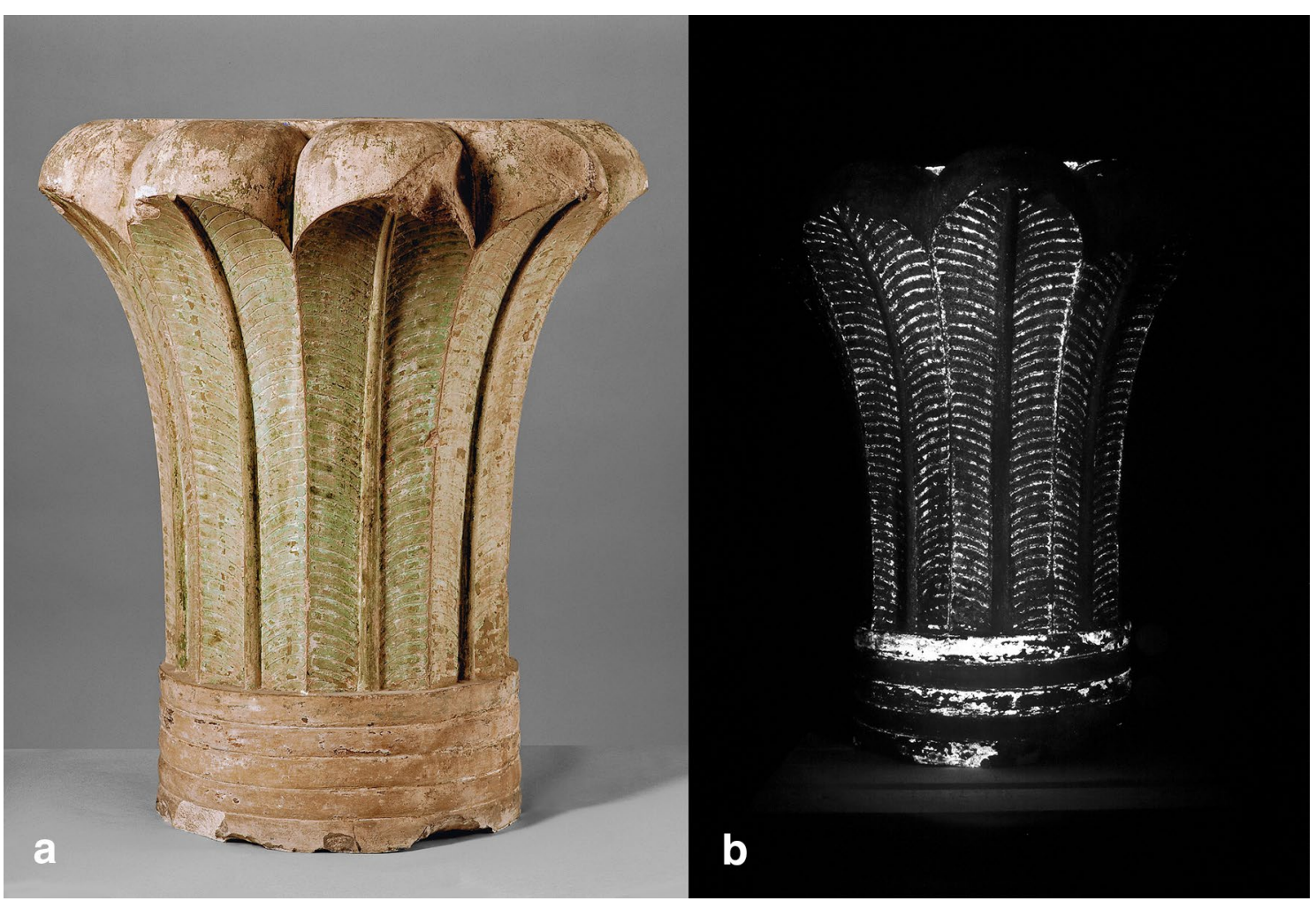

Fig. 1 a Column capital from the Palace of Apries. Ny Carlsberg Glyptotek, inv. no. AIN 1045. a Optical photo: Ole Haupt; b VIL image showing the distribution of Egyptian blue on the capital: Rikke Hoberg Therkildsen

of a feather of a Wepwawet standard is visible. There are rich traces of colour on the fragment: the horns appear greenish brown, the road blue, and the feather yellow with red outlining. The colourful paint layers appear to have been applied on top of the white background colour. Preparatory lines are visible delineating the road (Fig. 2c).

\section{AEIN 1060 [50]}

The fragment bears decoration in the form of a lotus leaf with a long vertical shaft. The decoration is carved in relief and is painted green, yellow, and ivory on a white background. The motif is outlined in black (Fig. 2d).

\section{Methodology and analytical apparatus}

The investigation is largely based on non-invasive methods of analysis thus keeping invasive measures to a minimum. The five architectural fragments were first examined at the (NCG). The techniques employed include microscopy with a Leica M651 surgical microscope (max $40 \times$ ), ultraviolet fluorescence (UVF) examination, and visible-induced luminescence (VIL) imaging. All visual observations are supported by photographic documentation $[51,52]$. After the preliminary examination at the museum, the wall fragments were analysed with micro-X-ray fluorescence $(\mu-\mathrm{XRF})$ at CHART. Its extensive delicate decoration combined with its sheer weight (c. $1000 \mathrm{~kg}$ ) made it unnecessarily hazardous to move the capital ÆIN 1045 to CHART. Since it was not feasible to move the instrument or to analyse the capital in the exhibition space, ÆIN 1045 has not been included in the $\mu$-XRF analysis.

Informed by the non-invasive investigation, a sampling strategy for further analysis was made. In order to optically document and examine the two decoration schemes observed on ÆIN 1045, microsamples were collected for cross-sections. With the exception of $Æ I N ~ 1060$, all of the fragments included in this paper have been subjected to Fourier transform infrared (FTIR) spectroscopy as part of the preceding study on organic compounds [1]. Although the said FTIR analyses were conducted with binding media and coatings in mind, they are most useful when assessing the inorganic components. For this reason, two samples were collected from ÆIN 1060 for FTIR analysis. Furthermore, the complex composition of the yellow paint layers suggested by the $\mu$-XRF analysis required further analysis. Since sampling would leave the delicate details of the minute decoration on ÆIN 1058 less discernible, it was decided to exclude it from the 

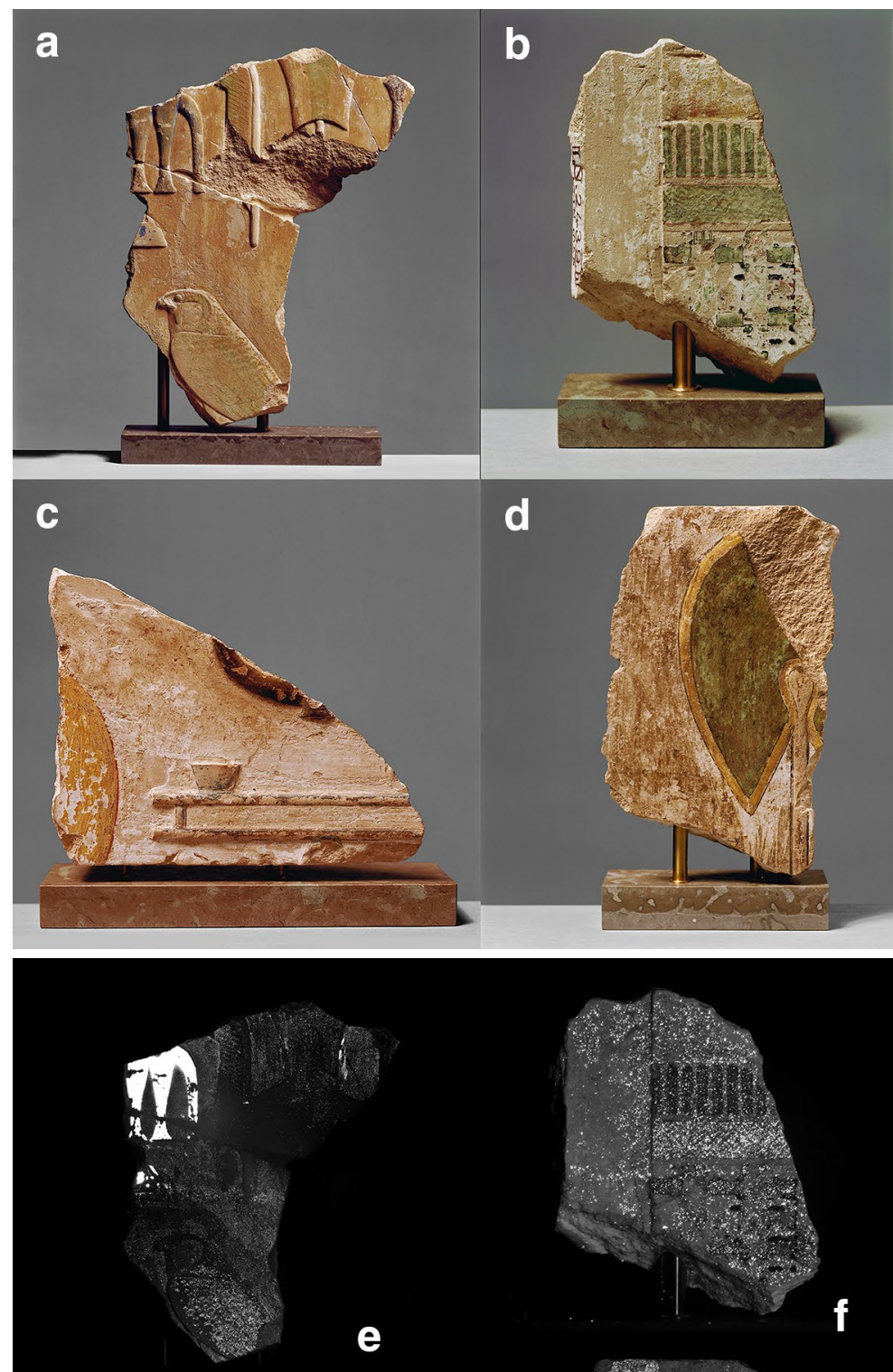

e
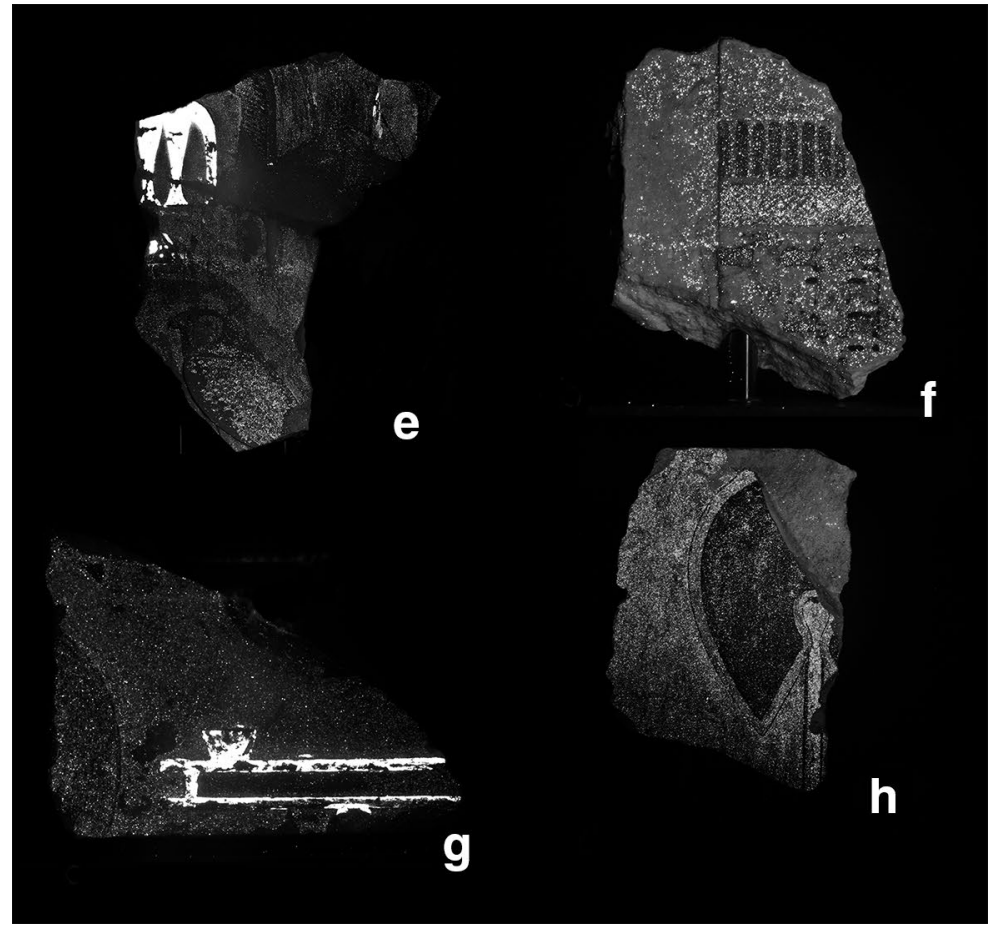

Fig. 2 Relief fragments from the Palace of Apries. Ny Carlsberg Glyptotek, inv. nos., 1048 (a) 1058 (b), 1059 (c), 1060 (d). Photos: Ole Haupt; b VIL images showing the distribution of Egyptian blue on the relief fragments from the Palace of Apries. Ny Carlsberg Glyptotek, inv. nos. 1048 (e) 1058 (f), 1059 (g), 1060 (h). VIL images: Maria Louise Sargent and Signe Buccarella Hedegaard 
invasive part of the investigation. A cross-section representing the somewhat thickly applied yellow paint layer on ÆIN 1059 was prepared and subjected to laser ablation inductively coupled plasma mass spectrometry (LAICP-MS) for more detailed information on its elemental composition. However, this did not resolve the issue satisfactorily. In order to fully understand the mineralogical composition of the yellow paint layers, a sample was collected for micro-X-ray powder diffraction ( $\mu$-XRPD) from ÆIN 1060 which has the most extensive yellow paint layer of the fragments in question. A more detailed description of the analytical methods used is given below.

\section{Visible-induced luminescence (VIL) imaging-Ny Carlsberg Glyptotek}

VIL imaging is an effective technique for the identification of the artificial pigment Egyptian blue.

This particular pigment has a unique property of absorbing visible radiation and reemitting it as infrared (IR) radiation in the $800-1000 \mathrm{~nm}$ range with a peak around $910 \mathrm{~nm}$. By capturing the luminescent emission with an IR-sensitive camera, Egyptian blue can be identified and its distribution documented [53].

VIL imaging was carried out using two Excled LED RGB lamps $\left(\lambda_{\max } 470 \mathrm{~nm}, 525 \mathrm{~nm}\right.$, and $\left.629 \mathrm{~nm}\right)$ and a Canon 40D camera modified by removing the internal IR-blocking filter. The lens was fitted with a Schott RG830 visible-blocking filter with an approximate IR sensitivity range of 800-1000 nm [54]. A Labsphere Spectralon $75 \%$ reflectance standard was included in each recorded image for the evaluation of the presence of luminescence. The VIL images have been edited using Adobe Photoshop Lightroom 2.7 and Adobe Photoshop CS6.

\section{Micro-X-ray fluorescence ( $\mu$-XRF)—CHART}

An ARTAX-800 $\mu$-XRF manufactured by Bruker-Nano was used for the $\mu$-XRF measurements. All colours distinguishable on each wall fragment were scanned. The beam size was $60 \mu \mathrm{m}$ in diameter. A high tension of $50 \mathrm{kV}$ and a current of $600 \mu \mathrm{A}$ were used. Typically, the live time for point analyses was $120 \mathrm{~s}$, and the dead time was $10-15 \%$. For mapping purposes, the live time was $3 \mathrm{~s}$ per pixel, and a spatial resolution of ca $100 \mu \mathrm{m}$ were used, making the acquisition time 4-8 $\mathrm{h}$ depending on the field of view. The net-area under the K-alpha or L-alpha lines was used to produce images of the elemental distributions. The penetration of $50 \mathrm{keV} \mathrm{X}$-rays is several micrometer and based on absorption calculations for the outgoing low energy X-rays (NIST-XCOM) it is apparent that the analyses reflect a layer of approximately 1-20 $\mu \mathrm{m}$ thickness depending on the chemistry of the outermost layer.

Absolute calibration of the concentrations has been performed by the DCCR-method (Direct Calibration from Count Rates) provided by the Bruker software using the standard reference material NIST-610 and the S concentration value of $570 \pm 70 \mu \mathrm{g} \mathrm{g}^{-1}$ for the NIST-610 as determined by Guillong et al. [55]. The results can only be considered semi-quantitative because of the difference between the glass of the NIST-610 standard material and the matrix of the samples. In some instances, a BAM RS3 calcium carbonate standard was used for absolute calibration of the $\mathrm{Ca}$ and $\mathrm{Sr}$ values.

\section{Cross-sections-Ny Carlsberg Glyptotek}

Eleven samples the sizes of a pinhead were collected from the capital ÆIN 1045 in order to document and compare its two decoration schemes. ${ }^{4}$ In addition, sample material was collected from the yellow paint layer on ÆIN 1059. All samples were collected from fractured areas limiting the damage caused by sampling to a minimum. Sampling was carried out with a clean scalpel. The specimens were stored in glass containers until processed. In most cases, the sample material broke into smaller pieces whereof two or more were selected and made into individual cross-sections. Each sample was placed in an EasySection mould and embedded in Struers Serifix polyester resin. After hardening, the resin-embedded samples were polished manually from one side first with $\mathrm{SiC}$ paper of increasing fineness $\left(800-4000\right.$ grains $\left.\mathrm{cm}^{-2}\right)$ on a Struers Knuth-Rotor 3 polishing machine and then manually with Micro-Mesh polishing sheets $(6000,8000$, and 12,000 grains $\mathrm{cm}^{-2}$ ).

The finished cross-sections were examined with a Leica DM2500M optical microscope $(\max 100 \times)$ in bright field, dark field and UV. All observations were documented with a Canon EOS 5D Mark II camera mounted on the microscope.

\section{Fourier transform infrared spectroscopy (FTIR)-CHART}

Infrared spectra were recording in the attenuated total reflection mode using a PerkinElmer 65 FT-IR spectrometer equipped with a $\mathrm{ZnSe}$ diamond crystal. Spectra were obtained in the range $4000-400 \mathrm{~cm}^{-1}$ range by accumulating 100 scans with a resolution of $4 \mathrm{~cm}^{-1}$.

\section{Laser ablation inductively coupled plasma mass spectrometry (LA-ICP-MS) - CHART}

Laser ablation (LA) was performed with a CETAC LXS213 G2 equipped with a NdYAG laser operating at a

\footnotetext{
${ }^{4}$ Sampling was carried out in two stages by two different conservators (M.Sc.). The first round, carried out by Rikke Hoberg Therkildsen, was focused on documenting all of the colours observed on the capital (blue, different green hues, and gilding). The second round, carried out by Signe Buccarella Hedegaard, was focused on documenting the sequence of the two decoration schemes on different parts of the large artefact.
} 
wavelength of $213 \mathrm{~nm}$. A $10 \mu \mathrm{m}$ circular aperture was used. The shot frequency was $20 \mathrm{~Hz}$. The line scan was performed with a scan speed of $5 \mu \mathrm{m} \mathrm{s}^{-1}$ and the thickness of the embedded sample was c. $166 \mu \mathrm{m}$. The helium

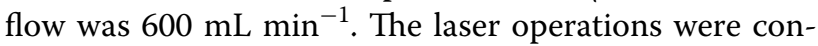
trolled by the DigiLaz G2 software provided by CETAC.

Inductively coupled plasma mass spectrometry (ICPMS) analyses were carried out using a Bruker Aurora M90 equipped with a frequency matching RF-generator. The basic parameters were as follows: radio frequency power $1.30 \mathrm{~kW}$; plasma argon gas flow rate $16.5 \mathrm{~L} \mathrm{~min}^{-1}$; auxiliary gas flow rate $1.65 \mathrm{~L} \mathrm{~min}^{-1}$; sheath gas flow rate $0.18 \mathrm{~L} \mathrm{~min}^{-1}$. The following isotopes were measured all without skimmer gas: Na23, Mg24, Al27, Si29, S33, K39, Ca44, Ti49, V51, Mn55, Fe57, Cu65, As75, Sr88, Ag107, Sn118, Sb121, Ba137, Au197 and Pb208. No interference corrections were applied to the selected isotopes. The analysis mode used was peak hopping using 3 points per peak. The dwell time on each peak was $1 \mathrm{~ms}$ and the total scan time for all the selected elements was c. $179 \mathrm{~ms}$. The data was subjected to a 5-point averaging filter.

The attempt was made to produce a list of semi-quantitative average concentrations in the homogeneous phases. The quantification was performed by first adjusting the count rate for the isotopic abundance for each isotope analysed. Then the shape of the count rate as a function of atomic number was determined by analysing seven elements in a $1 \mathrm{ppb}$ multi-element standard (ICP multi-element standard solution XXI for MS, by Accustandard). The isotopes used were $\mathrm{Be} 9, \mathrm{Mg} 25, \mathrm{Co5} 9$, In115, Ce140, Pb206, and Th232. The expected count rate in a $1 \mathrm{ppb}$ solution of the isotopes analysed for in this study was then calculated by interpolation between the measured count rates of these seven isotopes. Finally, the conversion from count rate to weight percent was done by multiplying by a fixed ratio, determined by taking the average of the measurements in the white ground layer, and assuming that the Ca concentration was $40 \mathrm{wt} \%$ (corresponding to pure $\mathrm{CaCO}_{3}$ ).

\section{Micro X-ray powder diffraction ( $\mu$-XRPD) - CHART}

The analysis was performed using a PANalytical X'Pert PRO MPD system (PW3050/60) with $\mathrm{Cu}$ Ko radiation as the source $(\lambda=1.54 \AA$ ) and a PIXcel3D detector. The $\mathrm{X}$-ray generator was set to an acceleration voltage of $45 \mathrm{kV}$ and a filament emission current to $40 \mathrm{~mA}$. The divergence slit was fixed at $0.43^{\circ}$. The capillary sample holder was mounted in an HTK 1200 N Capillary Extension (Anton Paar) with a ceramic anti-scatter shield. The sample was scanned while spinning between $5^{\circ}(2 \theta)$ and $90^{\circ}(2 \theta)$ using a step size of $0.013^{\circ}(2 \theta)$ with a count time of $260 \mathrm{~s}$. Data were collected using X'Pert Data Collector.
The qualitative analysis was performed using Highscore Plus software and Crystal Impact Match software. The ICDD PDF-2 database and the updated COD database have been used to interpret the results.

\section{Results \\ Capital ÆEIN 1045}

The VIL images show quite convincing patterns of photoluminescence emission consistent with the presence of Egyptian blue (Fig. 1b). The blue-painted areas observed on the base as well as the areas between the palm leaves at the top of the capital display very bright, coherent luminescence indicating a high concentration of Egyptian blue. Slightly less intense luminescence is observed on the palm leaves in the form of veins radiating from the midribs. The slight reduction in intensity suggests a smaller, yet considerable amount of Egyptian blue. This is in accordance with pigment mixtures containing a high concentration of the said blue pigment forming hues such as the dark, bluish-green colour used for the veins on the palm leaves.

Optical microscopic examination of the cross-sections attests to the presence of two decoration schemes on the palm leaves as well as the base of the capital. Both schemes comprise a white preparatory layer sequenced by one or more paint layers or gold leaf. Invariably, the second decoration scheme echoes the colours of the first (Fig. 3) suggesting that the capital was repainted in order to freshen up its original expression rather than to alter it. Furthermore, a greyish, waxy coating is observed covering a substantial part of the painted surface. According to the tentative pigment identification performed as part of the FTIR analysis in the binding media investigation, the green paint layer would appear to be based on atacamite [1].

\section{AEIN 1048}

VIL imaging strongly indicates the use of Egyptian blue in various concentrations (Fig. 2e). The blue-painted areas comprising the vases and their stand as well as the half loaf of bread all display very bright, coherent luminescence in the images attesting to a high concentration of Egyptian blue. The green-painted areas on the falcon below show a distinct, yet considerably less intense luminescence suggesting that the green paint layer contains some Egyptian blue. In addition, luminescing particles form part of the white background colour as well as other depicted details including the green feather and the animal skin. In these cases, however, the concentration is quite low.

The results of the $\mu$-XRF analyses also indicate unequivocally that the blue colour consists of Egyptian blue. As is shown in Fig. 4, $\mathrm{Cu}, \mathrm{Si}$, and $\mathrm{Ca}$ are all present 


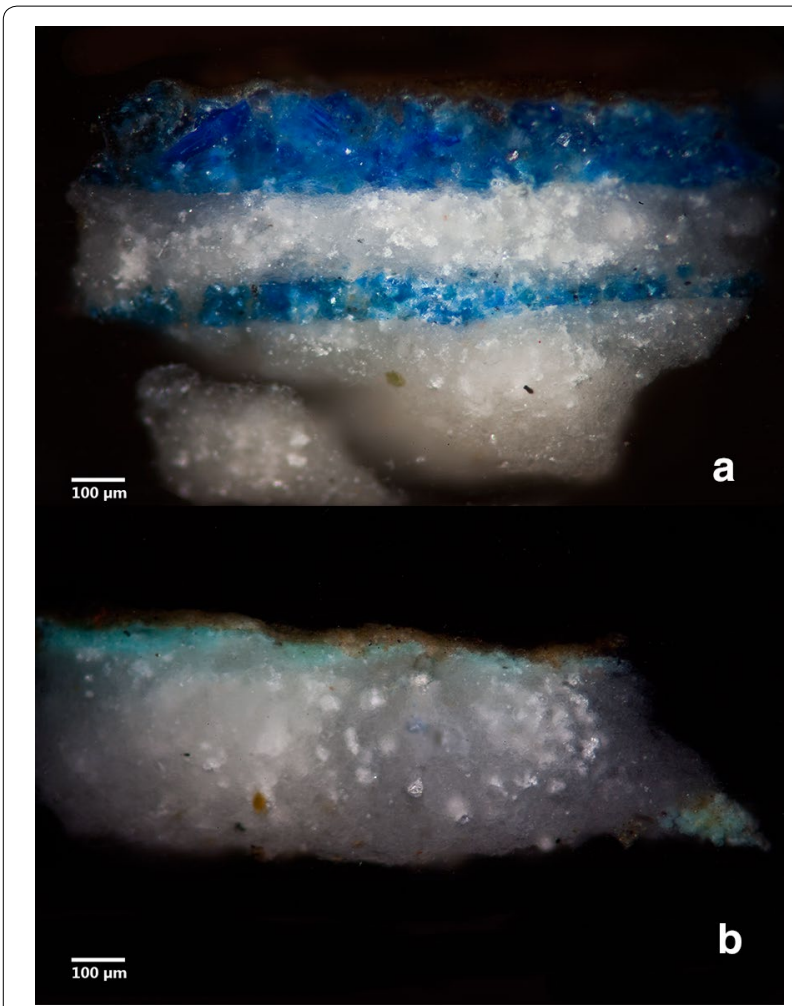

Fig. 3 Micrographs of two cross-sections representing a blue (a) and a green (b) paint layer on the palm capital ÆIN 1045. Two decoration schemes are visible in both cross-sections. The original ground layer is missing from the green sample (b). Original magnification $10 \times$. Photo: Signe Buccarella Hedegaard

in high concentrations in the blue-coloured areas, and no $\mathrm{Cl}$ is present (Fig. $4 \mathrm{~d}$ ). The green paint layer on the depicted feather contains high $\mathrm{Cu}$ and $\mathrm{Cl}$ concentrations (Fig. 5a, c) which points to the presence of atacamite $\left(\mathrm{Cu}_{2} \mathrm{Cl}(\mathrm{OH})_{3}\right)$. Slight amounts of $\mathrm{Mn}$ seem to follow the distribution of $\mathrm{Cu}$ and $\mathrm{Cl}$ (Fig. 5d). The concentration of $\mathrm{Si}$ in the green paint layer analysed (Fig. 5b) is too low to determine whether a minute amount of Egyptian blue $\left(\mathrm{CaCuSi}{ }_{4} \mathrm{O}_{10}\right)$ forms part of the painted decoration in this area, as suggested by VIL imaging. The distribution of $\mathrm{Ca}$ and $\mathrm{S}$ shown in Fig. 5f, g indicates that the white layer underneath the green paint contains gypsum.

\section{AEIN 1058}

The VIL images show luminescent particles forming part of almost the entire polychromy (Fig. 2f). On closer inspection, however, the distribution of the luminescent particles is evidently consistent with the white layer serving as the background colour as well as a preparatory ground layer for the rest of the painted decoration. Only the black-painted areas appear completely dark, attesting to the absence of Egyptian blue. The yellow, red, and green nuances all exhibit glowing particles whose exact relation to the painted decoration is uncertain in that they may form part of the paint layers or/and of the white preparatory layer underneath.

Figure 6 shows an optical image of the area which has been analysed with $\mu$-XRF scanning. The same area has been mapped with $\mu$-XRF depicted in Fig. 7 . In the green areas, the $\mu$-XRF elemental distribution graphs mainly reveal the presence of $\mathrm{Cu}$ and $\mathrm{Cl}$ (Fig. 7a, b). Based on the VIL images and the very low amounts of $\mathrm{Ca}$ and $\mathrm{Si}$ detected, Egyptian blue is unlikely to be present in the green-painted areas (Fig. 7c, d). Like the case of $Æ I N$ 1048, the high amount of $\mathrm{Cu}$ and the presence of $\mathrm{Cl}$ is pointing to the presence of atacamite. The yellow paint layer in the scanned area shown in Fig. 6 is characterised by high amounts of As (Fig. 7e), which is suggestive of orpiment $\left(\mathrm{As}_{2} \mathrm{~S}_{3}\right)$, as well as $\mathrm{Pb}$ which indicates the presence of one or more lead-based components such as lead-antimonate $\left(\mathrm{Pb}_{2} \mathrm{Sb}_{2} \mathrm{O}_{7}\right)$ and lead-tin yellow $\left(\mathrm{Pb}_{2} \mathrm{SnO}_{4}\right)$.

The $\mu$-XRF scanning also showed high concentrations of iron delineating the cracks and dents in the paint layers (Fig. 7f) pointing towards the presence of minute particles of soil deposited in the cracks. A point analysis in a white area showed almost pure calcium carbonate with traces of gypsum.

\section{AEIN 1059}

The VIL image shows bright, coherent luminescence in the blue areas of the painted decoration consistent with a high concentration of Egyptian blue (Fig. 2g). In addition, luminescing particles are observed forming part of the white background colour. The concentration and distribution indicate a very small amount of Egyptian blue, presumably added for its cool, tinting effect. A similar pattern of luminescence is seen in the yellow-painted area. It is unclear whether the photoluminescent particles form part of the yellow paint or the white layer underneath it.

The presence of Egyptian blue in the blue-painted areas is confirmed by the high concentrations of $\mathrm{Cu}, \mathrm{Si}$, and $\mathrm{Ca}$ detected with $\mu$-XRF point analysis and scans. A greenpainted area has been analysed using the same approach (Fig. 8). The results of the calibrated semi-quantitative concentrations are listed in Table 1 . Besides the elements listed in the table, the Sn L-alpha line clearly visible at $3.44 \mathrm{keV}$ shows unequivocally that $\mathrm{Sn}$ is present in the green pigment. Chlorine is also present in Fig. 8. However, $\mathrm{Cl}$ cannot be quantified using the NIST-610 standard. The presence of $\mathrm{Cu}$ and $\mathrm{Cl}$ and the absence of $\mathrm{Si}$ are pointing to the use of atacamite. The detection of high amounts of $\mathrm{Ca}$ is likely caused by the X-ray beam 


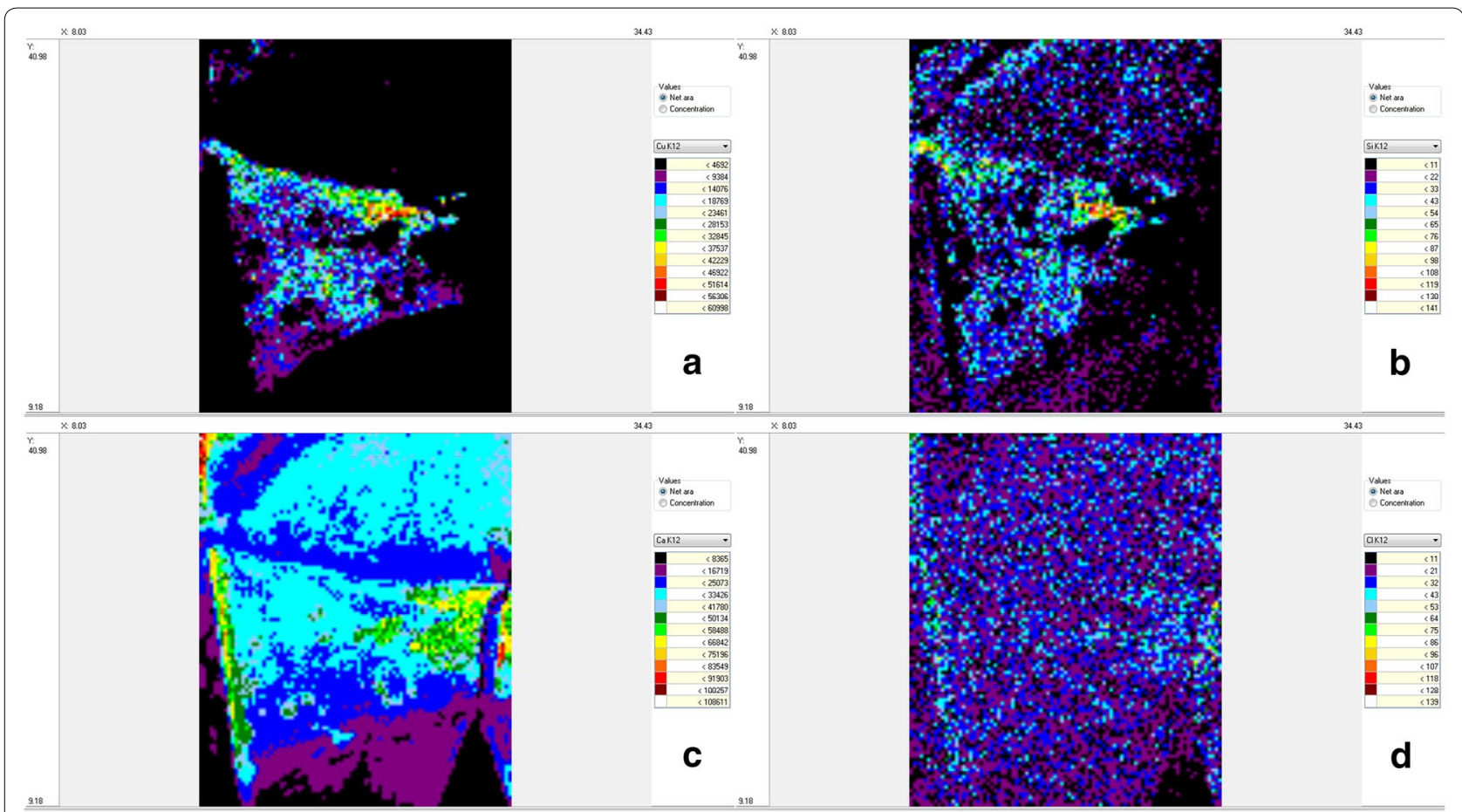

Fig. $4 \mu$-XRF elemental distribution plots of blue vase on ÆIN 1048. Cu (a), Si (b), Ca (c), Cl (d)

going through the thin green paint layer and reaching the underlying Ca-rich preparation layer.

A section of ÆIN 1059 comprising part of the yellow feather and the background was scanned with $\mu$-XRF (Fig. 9a). The pigment of the yellow paint contains large amounts of $\mathrm{Pb}$ and As. No S was seen in the white background (not shown in Fig. 9), and the white background is high in $\mathrm{Ca}$ and $\mathrm{Sr}$ (Fig. 9b, c), which makes it likely to be calcite. The red line is high in Fe (Fig. 9d) which makes it likely that the pigment is haematite $\left(\mathrm{Fe}_{2} \mathrm{O}_{3}\right)$. It is interesting to note that the area of high $\mathrm{Ca}$ (Fig. $9 \mathrm{~b}$ ) ends further towards the lower part of the field of view than the area of high Sr (Fig. 9c) so that a high concentration of $\mathrm{Sr}$ is also detected where it is covered by the red line and some part of the yellow paint. A likely explanation is that the K-alpha-line of $\mathrm{Sr}$ is so high in energy $(14.2 \mathrm{keV})$ that the photons escape even when covered by the red paint layer and some of the yellow paint layer, whereas the K-alpha-line of Ca has a relatively low energy $(3.7 \mathrm{keV})$, which causes an almost complete absorption of the $\mathrm{Ca}$ K-alpha photons on the way out from underneath the red and yellow paint. The fact that the yellow paint layer is only penetrable near the outline, indicates that the paint has been applied in a thicker layer in the rest of the yellow-painted area.

A single point analysis of the yellow pigments is shown in Fig. 10, and the results of the semi-quantitative concentrations are listed in Table 2. The main constituents are $\mathrm{Pb}$ and $\mathrm{As}$. The L-alpha line of $\mathrm{Pb}(10.551 \mathrm{keV})$ and the K-alpha line of As $(10.543 \mathrm{keV})$ overlap almost completely, but the L-beta line of $\mathrm{Pb}(12.61 \mathrm{keV})$ and the K-beta line of As $(11.73 \mathrm{keV})$ are clearly separated and distinguishable in the spectrum, and it is therefore clear that both $\mathrm{Pb}$ and As are present in the yellow pigment. Calcium and $\mathrm{Sr}$ are probably from the underlying ground layer. Even though there is a large Ca-signal (K-alpha, $4.0 \mathrm{keV}$ ) and K-signal (K-alpha, $3.6 \mathrm{keV}$ ) the $\mathrm{Sn} \mathrm{L-alpha}$ line at $3.4 \mathrm{keV}$ is visible as a shoulder. The Sn K-alpha lines at 25.0 and $25.3 \mathrm{keV}$ are also visible (although not depicted in Fig. 10). So, Sn is indeed identified by energy dispersive X-ray spectrum in appreciable amounts in the yellow paint. The K-lines for $\mathrm{Sb}$ is at 26.1 and $26.4 \mathrm{keV}$ are visible in the spectrum, but the L-alpha line of Sb situated at $3.6 \mathrm{keV}$ are swamped by the huge Ca system starting with K-alpha 1 at $3.69 \mathrm{keV}$ and extending to the K-beta line. From the $\mu$-XRF analyses it is therefore only possible to say that there is a small amount of Sb present based on the K-alpha line.

\section{AEIN 1060}

Apart from the thin black outlining, VIL imaging reveals varying concentrations of luminescent particles on the entire surface (Fig. 2h). The luminescence patterns observed are consistent with limited amounts of Egyptian 


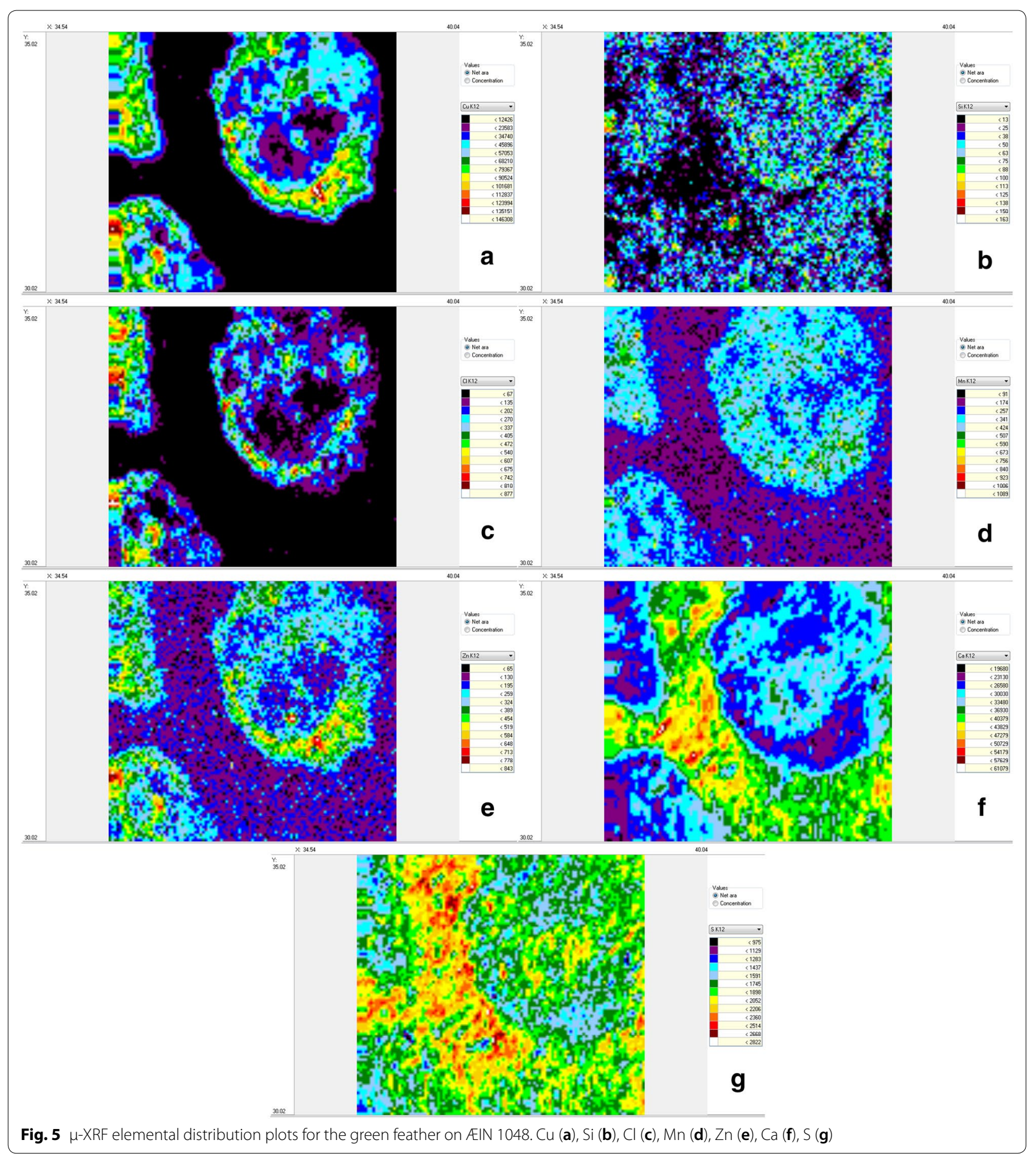

blue. The highest concentration is observed on the white shaft, the second highest on the white background and the yellow paint layers. The lowest concentration is found on the green area and the two widest black lines delineating the shaft. It is possible that Egyptian blue only forms part of the white nuances and that the luminescent particles observed on the other thinly applied paint layers stem from the white layer underneath. Considering the absence of luminescent particles on the finer lines delineating the motif, it would seem that the black paint used is not penetrable by VIL from underlying layers. It is probable that the particles observed on the black areas are to 


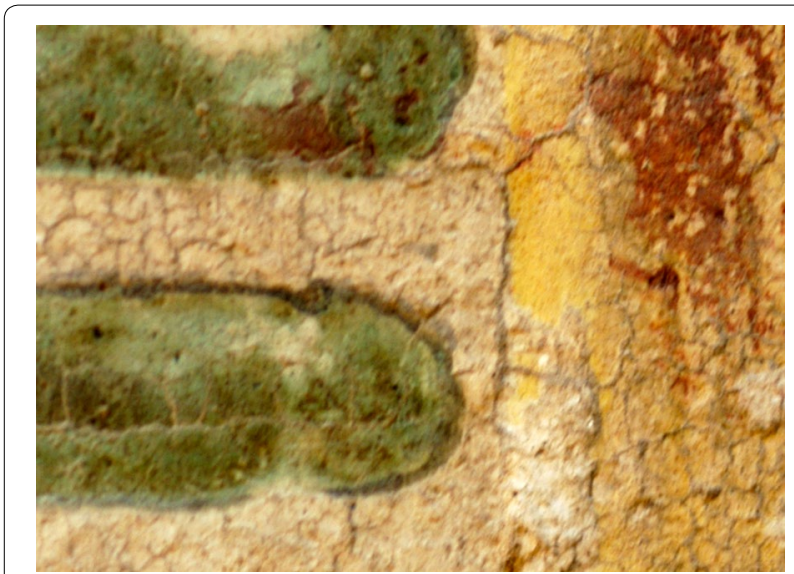

Fig. 6 Optical image of ÆIN 1058 showing the section analysed by $\mu$-XRF scanning be found on top of rather than within the paint layers. Particles of Egyptian blue are known to travel to neighbouring areas, $\mathrm{cf}$. the luminescent particles found on the broken surfaces of the painted relief.

The green paint was analysed by $\mu-\mathrm{XRF}$, the spectrum is shown in Fig. 11. The semi-quantitative results are listed in Table 3. A high concentration of $\mathrm{Cu}$ with some $\mathrm{Cl}$ has been detected in the green paint layer, making it likely that the pigment is atacamite. The low concentration of $\mathrm{Si}$ renders chrysocolla, and cupro-wollastonite improbable matches. The concentrations of $\mathrm{Ca}, \mathrm{Sr}$ and small amounts of $\mathrm{S}$ are probably ascribable to the presence of calcite and gypsum in the white layer underneath. Manganese, Fe, $\mathrm{Zn}$, and As are also detected in the green-painted area.

A sample of the green layer in ÆIN 1060 exhibited a FTIR spectrum with the typical bands of calcium oxalate $\left(\mathrm{CaC}_{2} \mathrm{O}_{4}\right)$ (Fig. 12). The bands are located at $1620 \mathrm{~cm}^{-1}$,

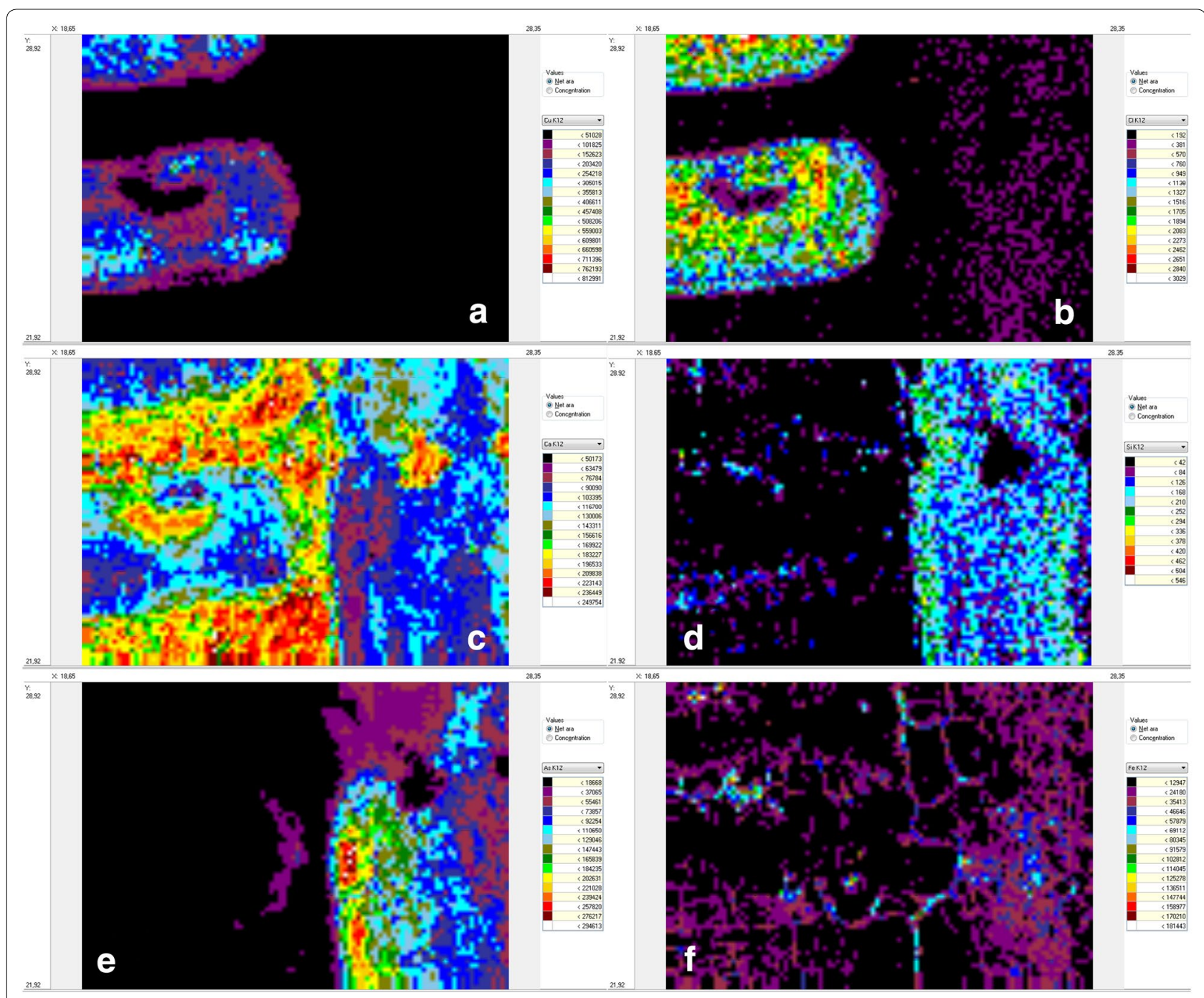

Fig. 7 Results of the $\mu$-XRF area scanning of area A-3 on AIN 1058. The figure shows the distribution of $\mathrm{Cu}(\mathbf{a}), \mathrm{Cl}(\mathbf{b}), \mathrm{Ca}(\mathbf{c}), \mathrm{Si}(\mathbf{d}), \mathrm{As}(\mathbf{e})$, and Fe (f) 

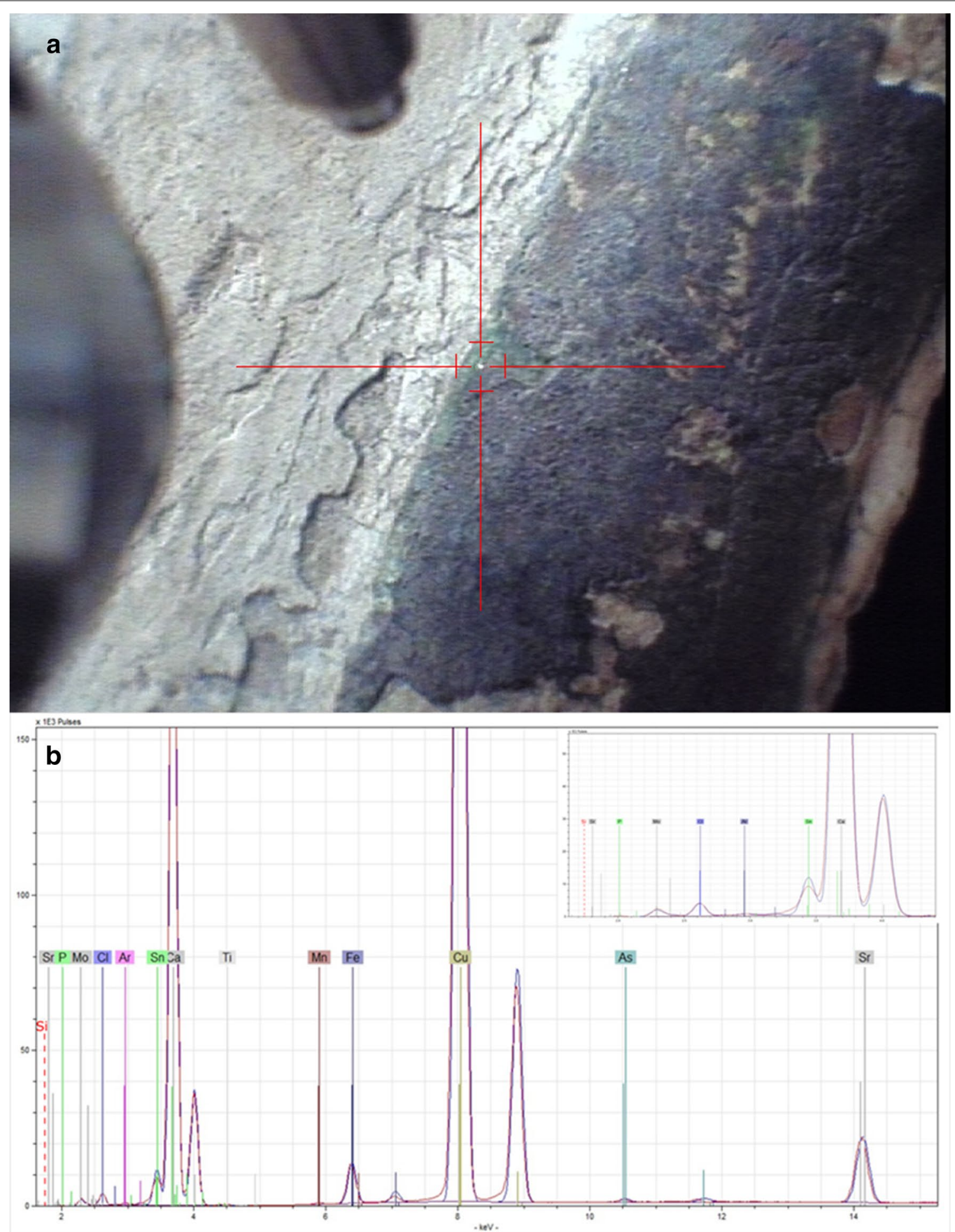

Fig. 8 A single point $\mu$-XRF analysis of the green pigment in AIN 1059: OM picture field of view from the ARTAX (a). The cross hair and the bright white laser spot marks the point of analysis; $\mathbf{b}$ energy dispersive X-ray spectrum. The main constituents are $\mathrm{Ca}$ and $\mathrm{Cu}$. Sr, Sn, and Fe are also present in appreciable amounts. Traces of $\mathrm{S}, \mathrm{Cl}, \mathrm{As}$, and $\mathrm{Pb}$ can be seen 
Table 1 DCCR calibrated results of the energy dispersive $X$-ray spectrum of a point analysis of the green pigment in AEIN 1059

\begin{tabular}{lllll}
\hline Element & Line & Conc./\% & Sigma/\% & RSD/\% \\
\hline $\mathrm{Ca}$ & K12 & 32 & 0.200 & 0.1 \\
$\mathrm{Mn}$ & $\mathrm{K} 12$ & 0.009 & 0.000 & 3.7 \\
$\mathrm{Fe}$ & $\mathrm{K} 12$ & 0.2 & 0.001 & 0.3 \\
$\mathrm{Cu}$ & $\mathrm{K} 12$ & 5.0 & 0.002 & 0.0 \\
$\mathrm{As}$ & $\mathrm{K} 12$ & 2.9 & 0.07 & 2.6 \\
$\mathrm{Sr}$ & $\mathrm{K} 12$ & 0.2 & 0.000 & 0.2 \\
$\mathrm{~Pb}$ & $\mathrm{~L} 1$ & 0.002 & 0.000 & 8.3 \\
\hline
\end{tabular}

"Line" designates the detected X-ray line; Conc. is the calibrated concentration of the element in weight \%; Sigma is one standard deviation; and RSD is the relative standard deviation expressed in $\%$. The results should be interpreted with some caution because the DCCR calibration is performed with the NIST SRM 610 whose matrix is different from that of the sample. As there is no reported $\mathrm{Cl}$ or $\mathrm{Sn}$ values for NIST SRM 610, the absolute $\mathrm{Cl}$ and Sn concentration cannot be calculated for $\mathrm{Cl}$ using the DCCR method. However, a less than semiquantitative approximation estimate based on the net counts gives approximate concentrations of c. $1 \mathrm{wt} \%$ of $\mathrm{Cl}$ and c. $0.1 \mathrm{wt} \%$ for $\mathrm{Sn}$ in this sample

$1318 \mathrm{~cm}^{-1}, 1092 \mathrm{~cm}^{-1}$, and $780 \mathrm{~cm}^{-1}$ and can be attributed to asymmetric $\mathrm{C}=\mathrm{O}$ stretch band, symmetric $\mathrm{C}=\mathrm{O}$ stretch band, asymmetric $\mathrm{C}-\mathrm{O}$ stretch band, and $\mathrm{O}-$ $\mathrm{C}=\mathrm{O}$ stretch band in calcium oxalate, respectively. The other bands detected in this spectrum fit well with data published for atacamite $\left(\mathrm{Cu}_{2} \mathrm{Cl}(\mathrm{OH})_{3}\right)$ [56]. The $\mathrm{CuCl}$ and $\mathrm{CuO}$ vibrations were detected at $415 \mathrm{~cm}^{-1}, 448 \mathrm{~cm}^{-1}$, $511 \mathrm{~cm}^{-1}$, and $598 \mathrm{~cm}^{-1}$. Deformation bands of hydroxyl are identified at $870 \mathrm{~cm}^{-1}, 913 \mathrm{~cm}^{-1}$, and $997 \mathrm{~cm}^{-1}$ as well as two hydroxyl stretching bands at $3316 \mathrm{~cm}^{-1}$ and $3440 \mathrm{~cm}^{-1}$. The results are in agreement with the $\mu$-XRF measurements and the FTIR results published for the sample ÆIN 1045 from the Palace of Apries [1].

Some very small intensity peaks that could belong to malachite $\left(\mathrm{Cu}_{2} \mathrm{CO}_{3}(\mathrm{OH})_{2}\right)$ can be seen in the spectrogram at $1490 \mathrm{~cm}^{-1}, 1384 \mathrm{~cm}^{-1}, 1043 \mathrm{~cm}^{-1}$, and $570 \mathrm{~cm}^{-1}$ (Fig. 12). However, other expected malachite peaks of strong and medium intensities are not seen in the spectrum, namely those located at $804 \mathrm{~cm}^{-1}, 821 \mathrm{~cm}^{-1}$, $750 \mathrm{~cm}^{-1}$, and $523 \mathrm{~cm}^{-1}[56,57]$. It is therefore most likely that malachite is not present in ÆIN 1060.

The yellow paint layer has also been analysed with $\mu$-XRF (Fig. 13) and the semi-quantitative results are listed in Table 4. The concentrations of As and S indicate that the yellow pigment is orpiment.

A micrograph of the white paint at the tip of the shaft is shown in Fig. 14 along with the energy dispersive spectrum of a single point analysis (Table 5). The paint layer is clearly white. However, the $\mathrm{Ca}$ determination is far from the expected $40 \mathrm{wt} \%$ (corresponding to $100 \% \mathrm{cal}$ cium carbonate) - only $19.4 \mathrm{wt} \%$ (see Table 6). There are also appreciable amounts of As and $\mathrm{S}$ present pointing towards the presence of some orpiment (Table 5). A likely interpretation is that the white paint, which cannot be securely identified by $\mu$-XRF, contains some orpiment. There is nothing arguing against the white paint being mainly calcium carbonate with a minor amount of gypsum or anhydrite, but the issue cannot be resolved by $\mu$-XRF alone, wherefore a small sample was procured for FTIR.

The FTIR spectrum of this sample from the white layer in ÆIN 1060 exhibited three bands belonging to calcium carbonate $\left(\mathrm{CaCO}_{3}\right)$ (Fig. 15). The bands located at $1420 \mathrm{~cm}^{-1}, 873 \mathrm{~cm}^{-1}$ and $713 \mathrm{~cm}^{-1}$ can be assigned to the v3-asymmetric $\mathrm{CO}_{3}$ stretching band, the $v 2$-asymmetric $\mathrm{CO}_{3}$ deformation band and the $v 1$-symmetric $\mathrm{CO}_{3}$ deformation band, respectively. Their location suggests a micritic texture of the calcium carbonate more than a sparitic one [58]. The bands located at $600 \mathrm{~cm}^{-1}$, $1000 \mathrm{~cm}^{-1}, 1150 \mathrm{~cm}^{-1}$ and the wide one centred around $3378 \mathrm{~cm}^{-1}$ could be due to the presence of gypsum. However, the shapes of the bands are not entirely typical for gypsum since the one at $600 \mathrm{~cm}^{-1}$ is quite sharp, while it usually forms a doublet or a triplet [59]. Bands from $\mathrm{SO}_{4}{ }^{2-}$ and $\mathrm{H}_{2} \mathrm{O}$ vibrations, which are usually seen in FTIR spectra of gypsum, are missing here. The identification of gypsum in the white layer can therefore only be tentative. The presence of an organic compound is seen with two bands at $2919 \mathrm{~cm}^{-1}$ and $2850 \mathrm{~cm}^{-1}$, both attributed to the $\mathrm{C}-\mathrm{H}$ stretching vibrations and a weak band detected at $1740 \mathrm{~cm}^{-1}$, which could belong to carbonyl groups. The broad band around $3400 \mathrm{~cm}^{-1}$ could be attributed to the NH-group. Taking the relatively low intensity of these bands into consideration, the identification of the organic compound(s) is uncertain. However, these observations are not contradicting the conclusions drawn from GC-MS-analysis performed on this sample, which points to the use of a binder mixed of plant gum and proteinaceous material [1].

\section{Further analyses of the yellow paint layers}

It would be interesting to know to which extent the yellow paint layers contain $\mathrm{Sb}$ or $\mathrm{Sn}$, as this would indicate the possible presence of lead-antimonate yellow or leadtin yellow. To resolve this, a sample of the paint layer from ÆIN 1059 was analysed using LA-ICP-MS. An optical image from the microscope is shown in Fig. 16a. The opposite side of this cut is shown in Fig. 16b, now seen through the optics of the laser ablator, after the laser ablation analysis was performed.

Very small count rates were seen for the isotopes $\mathrm{Na} 23$, Mg24, Al27, Si29, Ba137, and Au197, indicating that the concentrations of these elements were very low indeed. The detection limit of the ICP-MS is generally at the ppb to ppt level. Consequently, it is unlikely that $\mathrm{Na}, \mathrm{Mg}, \mathrm{Al}$, 


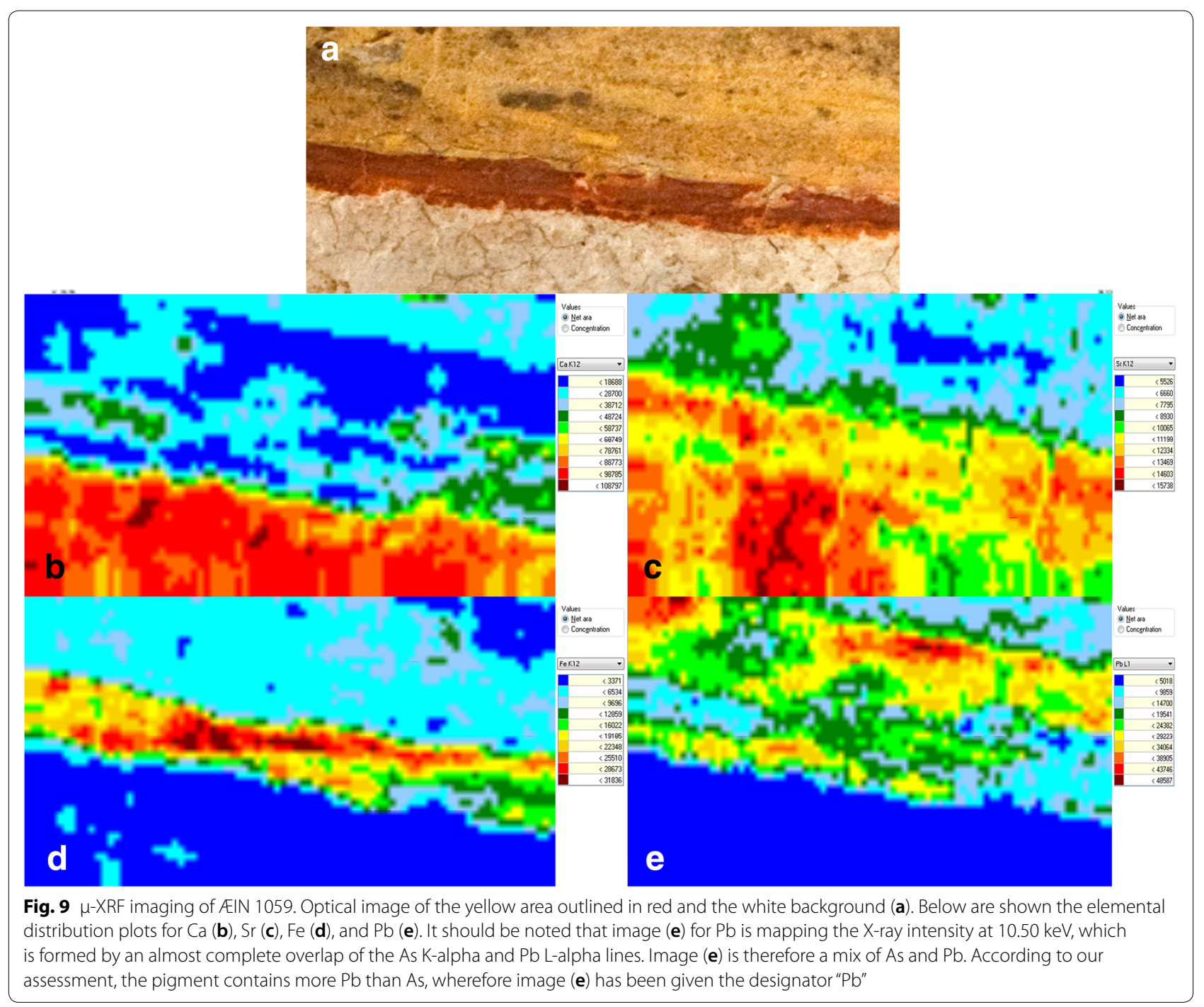

$\mathrm{Si}, \mathrm{Ba}$ and $\mathrm{Au}$ are present in concentrations over the $\mathrm{ppb}-$ level. The isotopes present in appreciable amounts are plotted in Fig. 17. Four groups of co-varying elements are discernible. The first group of four elements, at the top in Fig. 17 marked in red, $\mathrm{Pb}, \mathrm{Sb}, \mathrm{Cu}$, and $\mathrm{Ag}$ are present throughout the yellow paint layer with the highest concentrations in the lower part of the yellow paint layer. The next group consisting of Sn and As (curves marked in orange) features lower concentrations in the upper part and higher concentrations in the lower part of the yellow paint layer. Consequently, the first and the second groups are mainly distinguishable by $\mathrm{Sn}$ and As occurring in somewhat lower concentrations in the upper part of the yellow layer. The third group, Fe (marked in brown), is also present in the yellow paint layer, but with its highest concentration in the outer layer indicating that it is present in a separate mineral and has been applied last. Finally, there is the group consisting of $\mathrm{Ca}$ and $\mathrm{Sr}$ (marked in blue). They occur mostly in the white ground layer.

The LA-ICP-MS data shows the presence of both $\mathrm{Pb}$ and As in the yellow pigment in accordance with the $\mu$-XRF data. The LA-ICP-MS data also irrefutably show the presence of both $\mathrm{Sn}$ and $\mathrm{Sb}$ in substantial amounts. In the yellow paint layer, the isotope $\mathrm{Sn} 118$ has an average count rate of 14,300 counts s$^{-1}$ (Sn118 has a natural abundance of $24.2 \%$ ), while Sb121 has a count rate of 380,000 counts $\mathrm{s}^{-1}$ (this isotope has a natural abundance of $57.4 \%)$. Judging from the low count rates it is likely that $\mathrm{Ag}\left(645\right.$ counts s$\left.^{-1}\right)$ and $\mathrm{Cu}\left(567\right.$ counts s$\left.^{-1}\right)$ are only present in trace amounts. As described in the methodology section, the LA-ICP-MS measurements were calibrated to yield semi-quantitative concentrations (Table 7). The semi-quantitative calibration was done using the count rate for $\mathrm{Ca}$ in the white ground layer and assuming that the concentration of $\mathrm{Ca}$ here was $40 \mathrm{wt} \%$, consistent with 

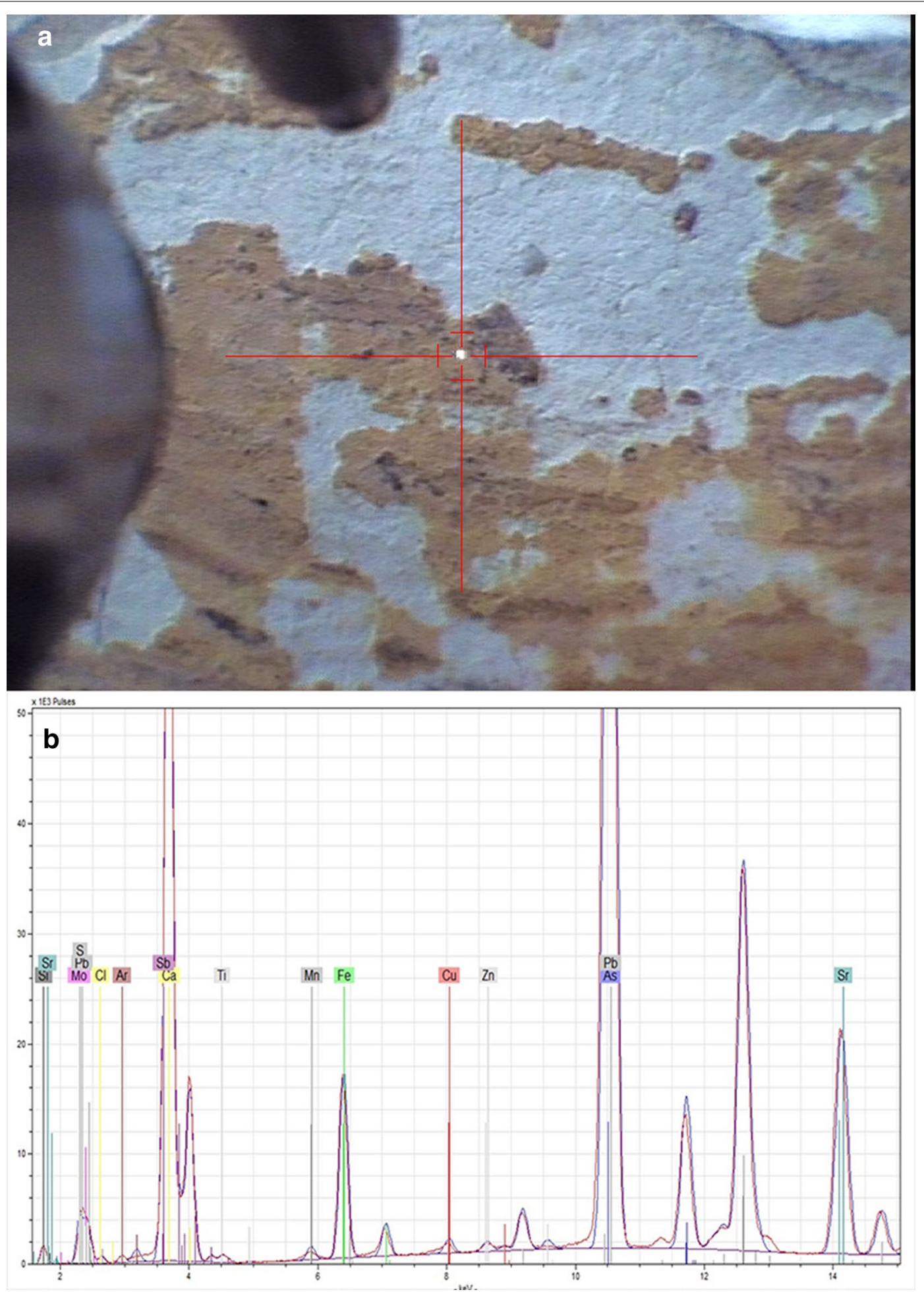

Fig. 10 A single point $\mu$-XRF analysis of the yellow-painted area (point A3, AIN 1059); a OM picture field of view from the ARTAX. The cross hair and the bright white laser spot marks the point of analysis; $\mathbf{b}$ energy dispersive $\mathrm{X}$-ray spectrum. The main constituents are $\mathrm{Pb}$ and $\mathrm{As}$. Calcium and $\mathrm{Sr}$ are probably from the underlying white layer. Also seen is Sn and Sb, and minor amounts of Si, S, Ti, Mn, Fe, Cu and Zn 
Table 2 DCCR calibrated results of the energy dispersive $X$-ray spectrum of a point analysis (A3, AIN 1059) of the yellow paint

\begin{tabular}{lllll}
\hline Element & Line & Conc./\% & Sigma/\% & RSD/\% \\
\hline $\mathrm{Si}$ & $\mathrm{K} 12$ & 18 & 0.15 & 0.9 \\
$\mathrm{~S}$ & $\mathrm{~K} 12$ & 1.6 & 0.008 & 0.5 \\
$\mathrm{Ca}$ & $\mathrm{K} 12$ & 12 & 0.013 & 0.1 \\
$\mathrm{Ti}$ & $\mathrm{K} 12$ & 0.04 & 0.001 & 1.9 \\
$\mathrm{Mn}$ & $\mathrm{K} 12$ & 0.03 & 0.000 & 1.4 \\
$\mathrm{Fe}$ & $\mathrm{K} 12$ & 0.3 & 0.001 & 0.2 \\
$\mathrm{Cu}$ & $\mathrm{K} 12$ & 0.01 & 0.000 & 1.6 \\
$\mathrm{Zn}$ & $\mathrm{K} 12$ & 0.009 & 0.000 & 2.5 \\
$\mathrm{As}$ & $\mathrm{K} 12$ & 2.9 & 0.003 & 0.1 \\
$\mathrm{Sr}$ & $\mathrm{K} 12$ & 0.2 & 0.000 & 0.2 \\
$\mathrm{~Pb}$ & $\mathrm{~L} 1$ & 0.8 & 0.001 & 0.1 \\
\hline
\end{tabular}

"Line" designates the detected X-ray line; Conc. is the calibrated concentration of the element in weight \%; Sigma is one standard deviation; and RSD is the relative standard deviation expressed in \%. The results should be interpreted with some caution because the DCCR calibration is performed with the NIST SRM 610 whose matrix is different from that of the sample

almost pure calcite. Using this assumption, we arrive at a concentration of $\mathrm{S}$ and $\mathrm{Sr}$ in the white ground layer of 0.8 and $1.6 \mathrm{wt} \%$ respectively. This indicates that the calibration is fairly robust; in particular it is clear that the amount of gypsum is relatively low in the ground layer, c. $4.1 \mathrm{wt} \%$, or even less if other sulphur-bearing minerals are present.

To ascertain if these minerals are actually present in the yellow pigment and if they are the only ones, a small sample was extracted from the yellow-painted area on of ÆIN 1060 (KLR-12084) and analysed using $\mu$-XRPD. Due to the thinness of the layers it was impossible to procure a sample of pure yellow pigment; the sample also contained visible fragments of the preparation layer and translucent wax together with yellow pigment.

The sample was crushed in an agate mortar and poured into a Pyrex capillary sample holder. The diffraction pattern (Fig. 18) showed the presence of two calcium related phases. Calcite was identified with many peaks fitting with the experimental pattern (PDF card 01-072-1652). Among them, the three peaks with the highest intensity were seen at $29.45^{\circ}(2 \Theta), 48.58^{\circ}(2 \Theta)$, and $39.42^{\circ}(2 \Theta)$, which correspond to the [104], [116], and [113] peaks respectively. The gypsum $\left(\mathrm{CaSO}_{4} \cdot 2 \mathrm{H}_{2} \mathrm{O}\right)$ pattern was also thoroughly consistent with the experimental diffractogram (PDF card 18-01-2012). The four peaks with the highest intensities are located at $20.72^{\circ}(2 \Theta), 11.63^{\circ}$ $(2 \Theta), 29.11^{\circ}(2 \Theta)$ and $31.16^{\circ}(2 \Theta)$. They correspond to the [-121], [020], [-141] and [121] peaks respectively. The low intensity of the peaks belonging to the gypsum phase confirm the observation made in the LA-ICP-MS analysis on ÆIN 1059 about the small quantity of this mineral in that sample. A small displacement $\left(<0.20^{\circ}\right)$ for the second and the third peaks of the gypsum can be seen. Reflections from wax were also present in the diffractogram, which agrees with the previous finding in the analyses of the binders [1]. The two main peaks were located at $21.48^{\circ}(2 \Theta)$ and $23.84^{\circ}(2 \Theta)$. Their high intensity reflects the relatively large amount of wax in the sample analysed.

According to the LA-ICP-MS results in ÆIN 1059, the yellow pigments could theoretically, i.e. stoichiometrically, be related to three specific phases in the sample: orpiment, lead-antimonate oxide and lead-tin oxide. The identification of orpiment (PDF card 01-071-2435) in the $\mu$-XRPD pattern of ÆIN 1060 is mainly based on the presence of the [020] peak with the highest intensity located at $18.51^{\circ}(2 \Theta)$. This peak is clearly visible despite the low intensity and it is not overlapped by any other phase. The peak with the second highest intensity is located at $32.99^{\circ}(2 \Theta)$ and corresponds to the [311] plane. This peak can be seen in the experimental pattern accepting a small shift $\left(\approx 0.3^{\circ}\right)$, however, the intensity is very low. The third and fourth peaks with higher intensities, if present in the diffractogram, are overlapped by gypsum and wax peaks. None of the other peaks with a lower intensity can be seen. This lack of smaller peaks and the slight shift for the second peak probably reflects a small number of orpiment grains in the sample.

Lead and antimony were found under different forms in the $\mu$-XRPD pattern of ÆIN 1060. The first oxide identified was the bindheimite $\left(\mathrm{Pb}_{2} \mathrm{Sb}_{2} \mathrm{O}_{6}\right)$, which is the natural mineral form of lead-antimony oxide (PDF card 00-0180687). However, this identification is mainly based on the peak with the highest intensity located at $29.71^{\circ}(2 \Theta)$ originating from the [222] plane. Despite being close to a calcite peak [104], this peak is clearly visible even if the intensity is relatively low. It should be noted that there is also a very low intensity wax peak at $29.95^{\circ}(2 \Theta)$. The other wax peaks with very low intensities are not visible in the pattern, thus this peak is very likely linked to the lead-antimony oxide phase. The peak with the second highest intensity is located at $49.50^{\circ}(2 \Theta)$ with a [440] plane. This peak was also identified in the experimental pattern, but its intensity is very low. This can be due to the difference between the relative intensities of the first and the second peak in the theoretical pattern of bindheimite (the I.R. of [440] peak decreases to 30\%). None of the other peaks with a lower intensity from this phase can be seen in the diffractogram. Another lead-antimony-based phase can tentatively be identified in the pattern as an iron-lead-antimony sulphide $\left(\mathrm{Pb}_{4} \mathrm{FeSb}_{6} \mathrm{~S}_{13}\right)$ (PDF card 00-041-1401). This phase is identified as parajamesonite in the PDF database. However, Papp et al. [60] have discredited this mineral identification by proving 

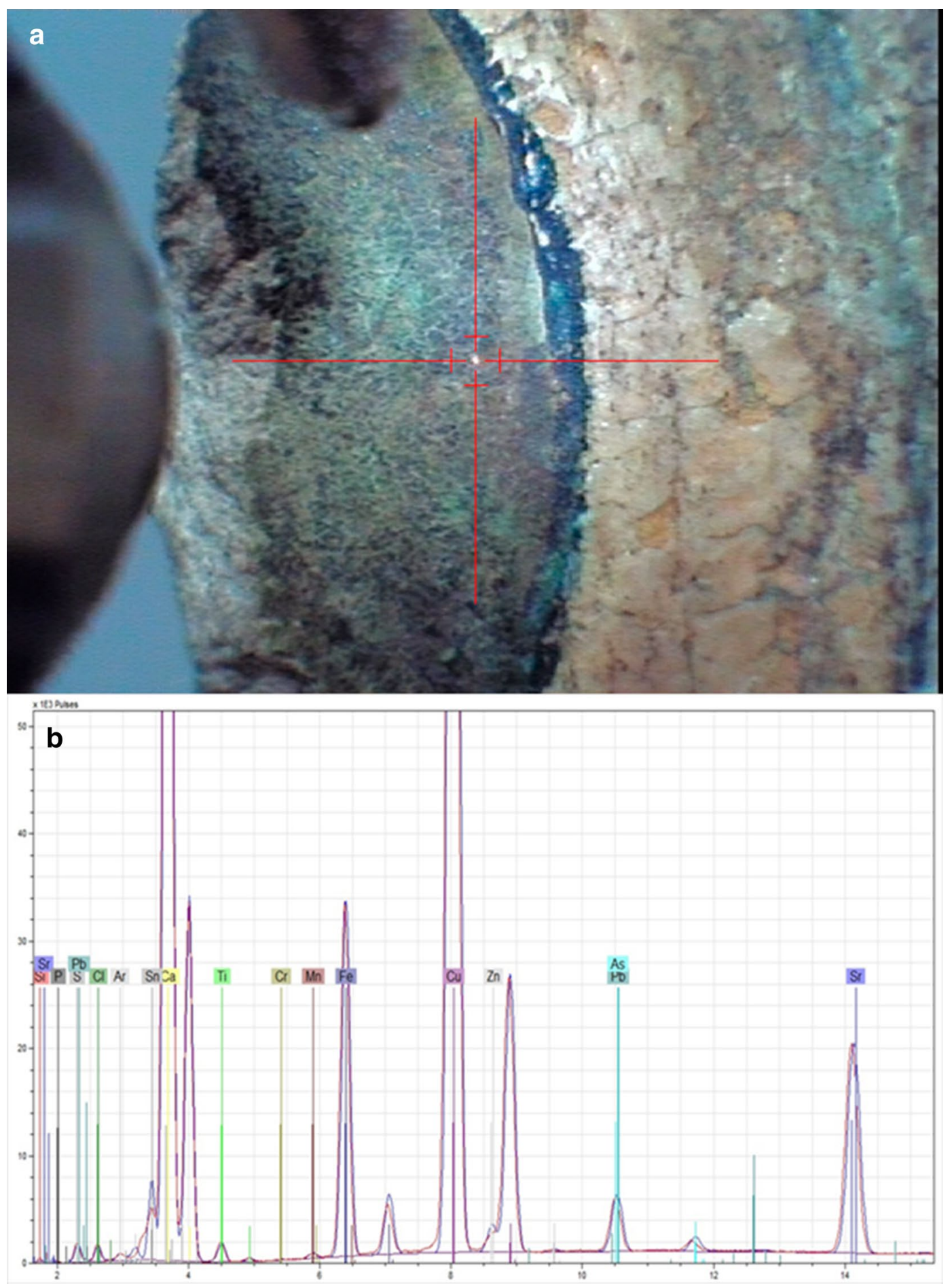

Fig. 11 A single point $\mu$-XRF analysis of the green-painted area of EIN 1060; a OM picture field of view from the ARTAX. The cross hair and the bright white laser spot marks the point of analysis; $\mathbf{b}$ energy dispersive $\mathrm{X}$-ray spectrum. Cupper and $\mathrm{Cl}$ are seen pointing towards atacamite. Calcium and $\mathrm{Sr}$ and small amounts of $\mathrm{S}, \mathrm{Mn}, \mathrm{Fe}, \mathrm{Zn}$, and As are also seen 
Table 3 DCCR calibrated results of the energy dispersive $X$-ray spectrum of a point analysis AEIN 1060 of the green paint

\begin{tabular}{|c|c|c|c|c|}
\hline Element & Line & Conc./\% & Sigma/\% & RSD/\% \\
\hline $\mathrm{Si}$ & K12 & 2.4 & 0.049 & 2.1 \\
\hline S & $\mathrm{K} 12$ & 0.6 & 0.005 & 0.8 \\
\hline $\mathrm{Ca}$ & $\mathrm{K} 12$ & 27 & 0.019 & 0.1 \\
\hline $\mathrm{Ti}$ & $\mathrm{K} 12$ & 0.1 & 0.001 & 0.8 \\
\hline $\mathrm{Mn}$ & $\mathrm{K} 12$ & 0.01 & 0.000 & 3.3 \\
\hline $\mathrm{Fe}$ & $\mathrm{K} 12$ & 0.6 & 0.001 & 0.2 \\
\hline $\mathrm{Cu}$ & $\mathrm{K} 12$ & 2.0 & 0.001 & 0.1 \\
\hline $\mathrm{Zn}$ & $\mathrm{K} 12$ & 0.03 & 0.000 & 1.0 \\
\hline As & $\mathrm{K} 12$ & 0.15 & 0.001 & 0.5 \\
\hline $\mathrm{Sr}$ & $\mathrm{K} 12$ & 0.2 & 0.000 & 0.2 \\
\hline $\mathrm{Pb}$ & L1 & 0.003 & 0.000 & 7.4 \\
\hline
\end{tabular}

Conc. is the calibrated concentration of the element in weight \%; Sigma is one standard deviation; and RSD is the relative standard deviation expressed in $\%$. The results should be interpreted with some caution because the DCCR calibration is performed with the NIST SRM 610 whose matrix is different from that of the sample. Besides the listed elements there was $\mathrm{Cl}$ present, which, however, cannot be properly calibrated

that the reference samples were mixtures of jamesonite and other mineral phases. Thus, this phase will only be named "iron-lead-antimony sulphate" according to its chemical composition. The two peaks with the highest intensity are located at $21.07^{\circ}(2 \Theta)$ and $23.49^{\circ}(2 \Theta)$. They are overlapped by the wax peaks. The third highest intensity peak is located at $19.09^{\circ}(2 \Theta)$. This peak can be seen in the pattern and is not overlapped by any other phase.
The fourth highest intensity peak is located at $40.38^{\circ}$ $(2 \Theta)$. The intensity of this line might be increased by the low intensity gypsum [-152] peak which is close. For this phase, the Miller index was not specified on the PDF card.

The lead-tin oxide was the third compound suggested by the LA-ICP-MS results of ÆIN 1059. However, a better match can be found in the $\mu$-XRPD pattern of ÆIN 1060 with a lead-tin-antimony oxide phase (PDF card 00-039-0928). The first peak with a [222] plane is located at $29.22^{\circ}(2 \Theta)$ but it is overlapped by the calcite [104] peak. The peaks with the second and the third highest intensity are also overlapped by the calcite [116] and calcite [122] peaks, respectively. The peaks with lower intensities cannot be seen in the XRD pattern. The presence of a goethite phase (COD card 96-900-2156) cannot be identified in the XRD pattern. The first peak with the highest intensity with a [101] plane is located at $21.35^{\circ}$ $(2 \Theta)$ but it would be overlapped by a wax peak. The other peaks with a lower intensity cannot be seen in the diffractogram.

In the $\mu$-XRPD pattern, wax, calcite, and gypsum are the most abundant and visible phases. Their signals somewhat conceal relevant parts of the other mineralogical phases, the presence of which was suggested by the LA-ICP-MS results on ÆIN 1059. Despite this drawback, it is possible to confirm the use of orpiment in the yellow

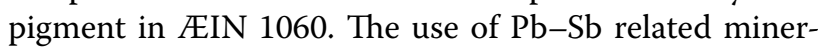
als was also confirmed, but more precise mineralogical identification cannot be achieved by way of the $\mu$-pXRD

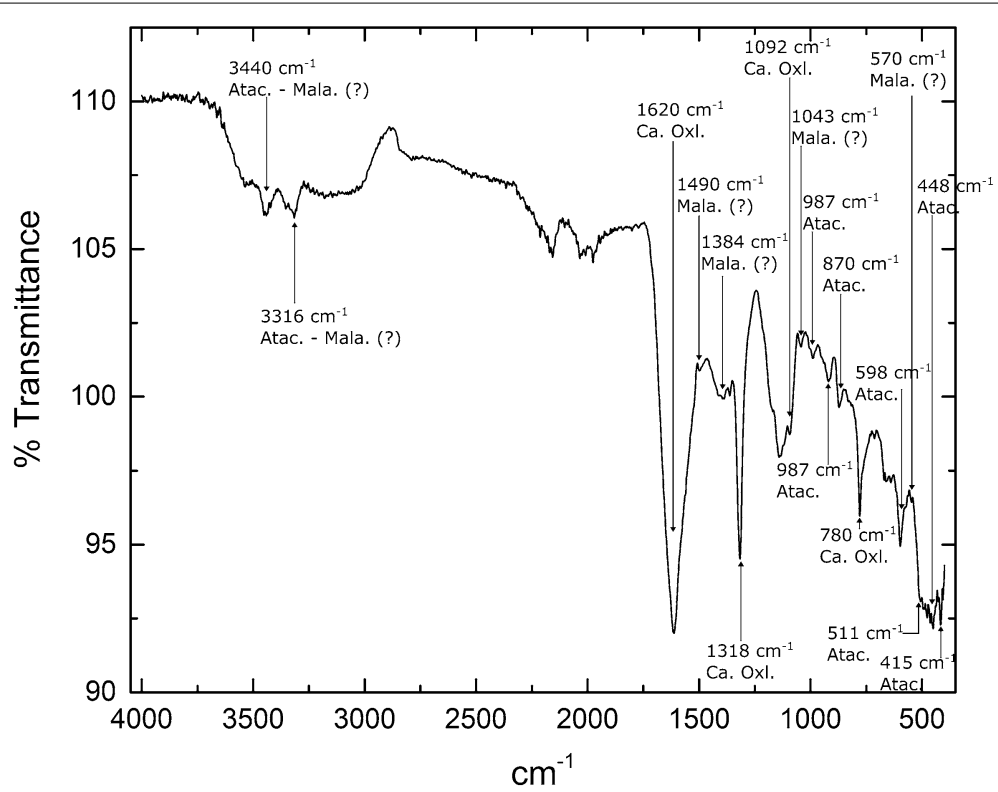

Fig. 12 FTIR spectrum of a small sample of green paint from ÆIN 1060. Characteristic lines of atacamite and calcium oxalate is seen. Tentatively marked are some minor lines of malachite. However, the major and medium intensity lines of malachite are not present in the spectrum 

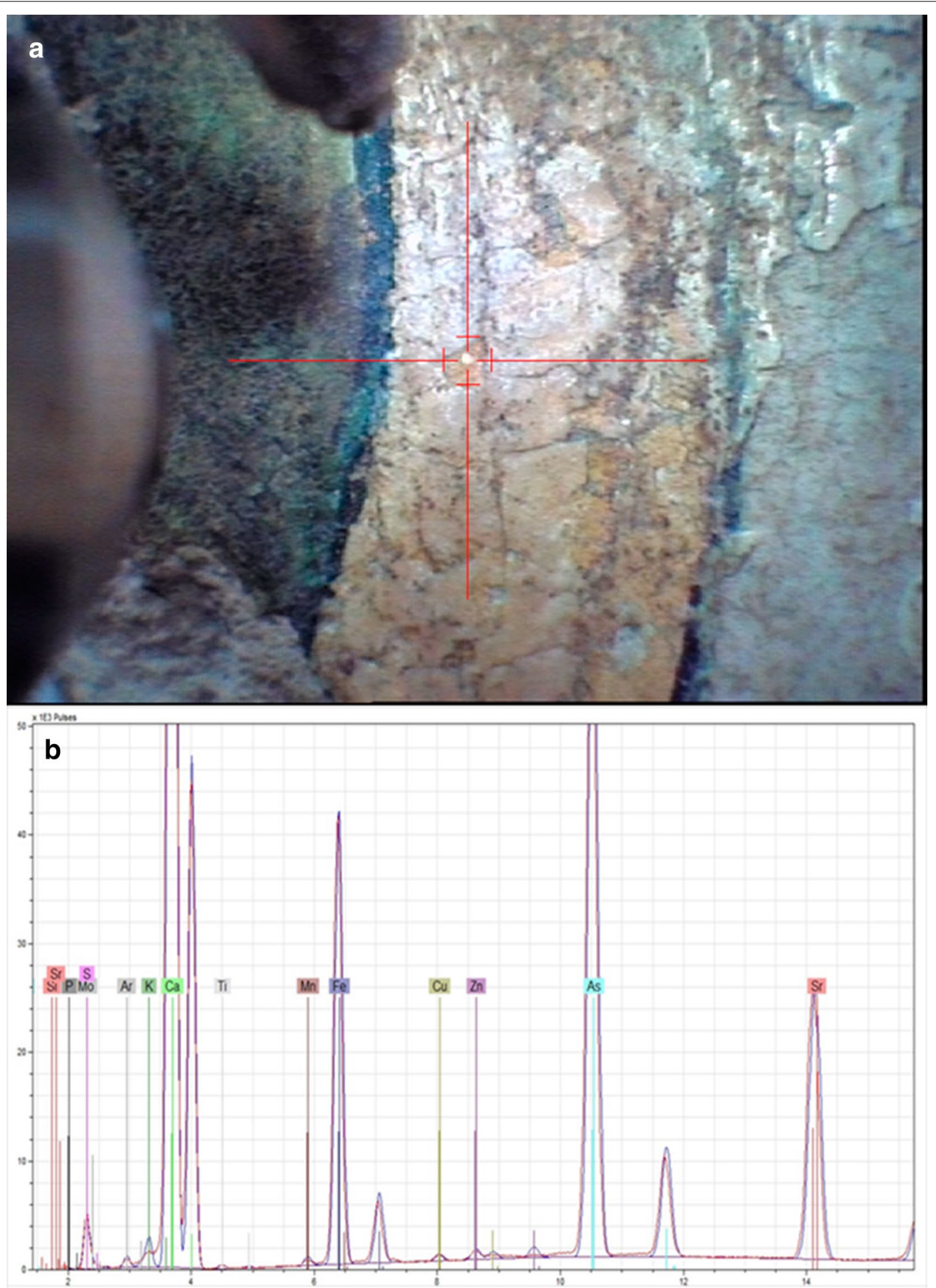

Fig. 13 A single point $\mu$-XRF analysis of the yellow-painted area pigment of ÆIN 1060; a OM picture field of view from the ARTAX. The cross hair and the bright white laser spot marks the point of analysis; $\mathbf{b}$ energy dispersive X-ray spectrum. Arsenic and $\mathrm{S}$ is seen in the spectrum. Also seen is Ca, Sr and minor amounts of $\mathrm{S}$ from the underlying grounder 
Table 4 DCCR calibrated results of the energy dispersive X-ray spectrum of a point analysis AIN 1060 of the yellow paint

\begin{tabular}{lllll}
\hline Element & Line & Conc./\% & Sigma/\% & RSD/\% \\
\hline $\mathrm{Si}$ & $\mathrm{K} 12$ & 0.001 & 0.001 & 99 \\
$\mathrm{~S}$ & $\mathrm{~K} 12$ & 1.7 & 0.008 & 0.5 \\
$\mathrm{Ca}$ & $\mathrm{K} 12$ & 37 & 0.022 & 0.1 \\
$\mathrm{Ti}$ & $\mathrm{K} 12$ & 0.01 & 0.000 & 3.9 \\
$\mathrm{Mn}$ & $\mathrm{K} 12$ & 0.02 & 0.000 & 2.0 \\
$\mathrm{Fe}$ & $\mathrm{K} 12$ & 0.7 & 0.001 & 0.1 \\
$\mathrm{Cu}$ & $\mathrm{K} 12$ & 0.006 & 0.000 & 3.2 \\
$\mathrm{Zn}$ & $\mathrm{K} 12$ & 0.01 & 0.000 & 2.1 \\
$\mathrm{As}$ & $\mathrm{K} 12$ & 2.0 & 0.002 & 0.1 \\
$\mathrm{Sr}$ & $\mathrm{K} 12$ & 0.3 & 0.000 & 0.2
\end{tabular}

Conc. is the calibrated concentration of the element in weight \%; Sigma is one standard deviation; and RSD is the relative standard deviation expressed in $\%$. The results should be interpreted with some caution because the DCCR calibration is performed with the NIST SRM 610 whose matrix is different from that of the sample. Besides the listed elements $\mathrm{Cl}$ was detected as well, which, however, cannot be properly calibrated

in this small sample. It seems possible that these phases are the result of a mixture of different compounds. The presence of sulphide and oxide could suggest that the $\mathrm{Pb}-\mathrm{Sb}$ oxide is, at least partially, the oxidation product of $\mathrm{Pb}-\mathrm{Sb}$ sulphide, or alternatively originates from the orpiment. The Sn and Fe related phases cannot be confirmed by $\mu$-XRPD, maybe because of overlap. However, it seems very likely that these elements would have been embedded in the $\mathrm{Pb}-\mathrm{Sb}$ oxide. Iron oxides usually occur along with other terrigenous minerals, such as clay, quartz or micas, and none of these are seen in the diffractogram. This particularity, together with the likely possibility of a mixture between different $\mathrm{Pb}-\mathrm{Sb}-\mathrm{Sn}$ bearing phases support the idea, that the preparation steps for the yellow pigment were very thorough (e.g. burning, sieving, waterwashing) in order for clay and quartz to be completely removed from the pigment.

From a methodological perspective, it should be noted that a lack of accuracy in the peak positions and missing peaks are well-known problems when using $\mu$-XRPD. This can be caused by at least four possible errors: small amounts of single crystals in the sample; the thinness of the cross section analysed; the particle statistic (smaller number of larger grains) and a possibly inhomogeneous distribution of grains [61].

Therefore, taking the results in their entirety, the most likely yellow pigment containing $\mathrm{Sb}$ is lead-antimonate yellow $\left(\mathrm{Pb}_{2} \mathrm{Sb}_{2} \mathrm{O}_{7}\right)$, and the only viable yellow pigment containing $\mathrm{Sn}$ is lead-tin yellow $\left(\mathrm{Pb}_{2} \mathrm{SnO}_{4}\right)$. These two pigments account for the presence of $\mathrm{Pb}, \mathrm{Sb}$, and $\mathrm{Sn}$, and probably small amounts of $\mathrm{Fe}$ and $\mathrm{S}$ also. It must be stated, that although these two identifications are not only possible, but also likely candidates, there is still room for other possible mineral identifications. The third mineral containing As is orpiment. In Table 7 are listed calculations of the amounts of the three mineral phases, made on the assumption that all $\mathrm{Sn}$ is present as lead-tin yellow, all $\mathrm{Sb}$ as lead antimonate yellow, and all As as orpiment. Thus, the results of the LA-ICP-MS on the yellow paint layer point to a mixture of lead-tin yellow $\left(\mathrm{Pb}_{2} \mathrm{SnO}_{4}\right.$, c. $\left.9.9 \mathrm{wt} \%\right)$, lead-antimonate yellow $\left(\mathrm{Pb}_{2} \mathrm{Sb}_{2} \mathrm{O}_{7}\right.$, c. 1.4 wt\%) with traces of $\mathrm{Ag}$ and $\mathrm{Cu}$, and orpiment $\left(\mathrm{As}_{2} \mathrm{~S}_{3}\right.$, c. $\left.0.95 \mathrm{wt} \%\right)$.These concentration calculations are consistent with most elements, but leaves c. $10 \mathrm{wt} \%$ of $\mathrm{Pb}$ unaccounted for. This extra $\mathrm{Pb}$ could be speculated to be present as degradation products of lead-tin yellow and lead-antimonate yellow.

\section{Discussion}

The palette identified therefore includes calcite, gypsum (or anhydrite), Egyptian blue, probably atacamite, haematite, lead-antimonate yellow, lead-tin yellow, and orpiment. A summary of the pigments identified are listed in Table 8.

\section{Painting techniques}

The investigation has shown that the limestone fragments have all been primed with a white ground layer [1]. This is consistent with the vast majority of examined examples of painted decoration from ancient Egypt [3, $62,63]$. In addition to its function as a preparatory layer, the white layer on the wall fragments also serves as the background colour for the painted decoration. There are countless examples of Egyptian decoration executed on a white background reflecting the same practice [3, 62]. Interestingly, it would appear that the ratios of calcite to gypsum depend on the pigments applied on top of the white ground. Thus, yellow-painted areas seem to have been painted on top of calcite with traces of gypsum or anhydrite, whereas the rest of the decoration is painted on top of gypsum or anhydrite with traces of calcite. A similar approach has been observed in an 18th-Dynasty wall painting at Thebes where orpiment has been applied on top of huntite and the rest of the decoration directly on the plastered walls. Although there may be an element of aesthetics involved as suggested by McCarthy [64], we believe this approach to be of a more practical nature. Considering that orpiment is known to be unstable in alkaline conditions and therefore incompatible with wet plaster in particular [65], it would make sense to apply an additional white ground layer of calcite or huntite in areas to be painted with orpiment.

In the painted decoration, the pigments often appear mixed with calcium-based compounds added for their brightening effect. Additional colour mixing appears 

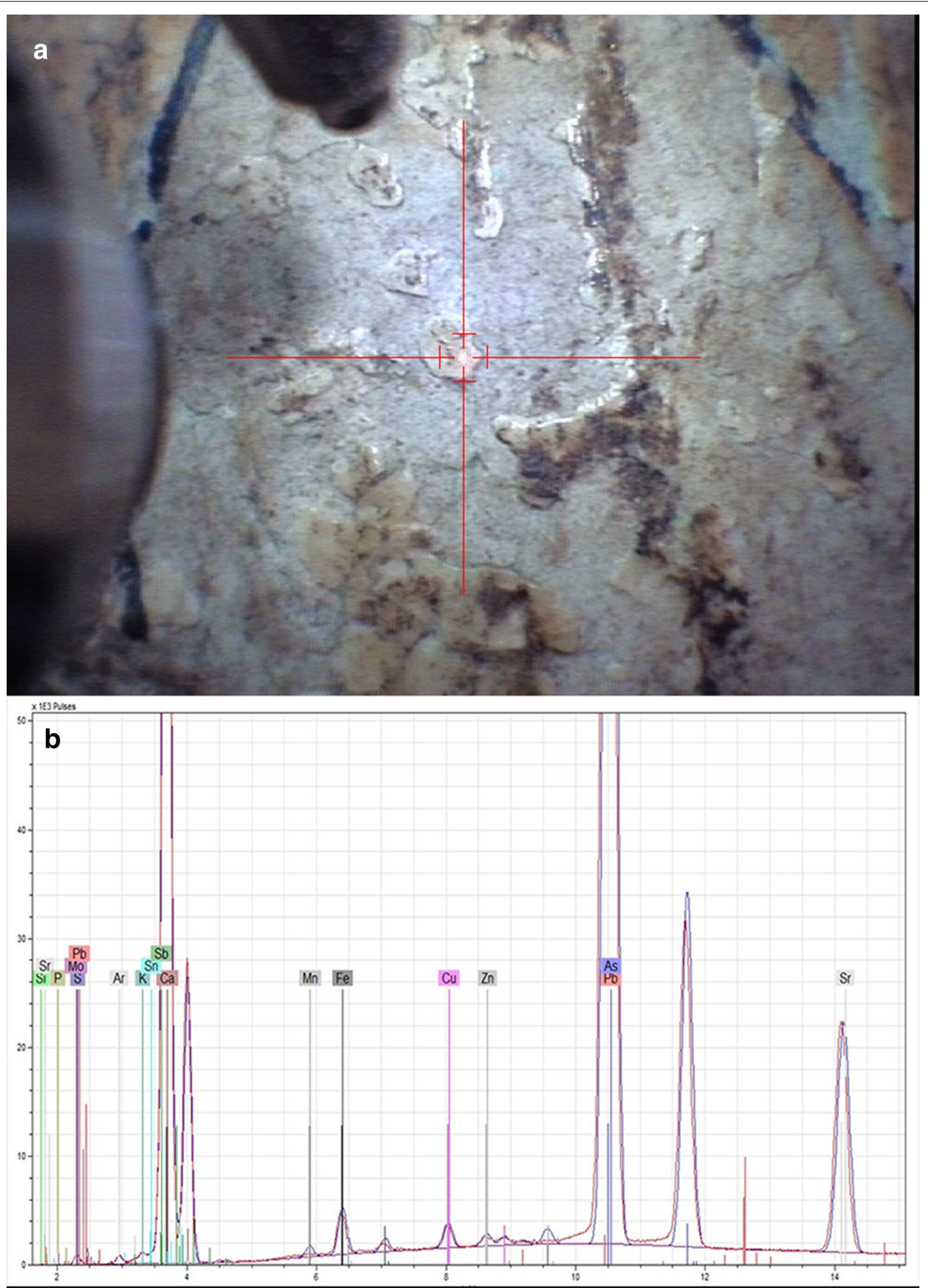

Fig. 14 A single point $\mu$-XRF analysis of the white-painted shaft on AEIN 1060; a OM picture field of view from the ARTAX. The cross hair and the bright white laser spot marks the point of analysis; $\boldsymbol{b}$ energy dispersive X-ray spectrum. This fit shown is that of using NIST-610 for DCCR calibration 
Table 5 DCCR calibrated results of the energy dispersive X-ray spectrum of a point analysis AIN 1060 of the white paint

\begin{tabular}{lllll}
\hline Element & Line & Conc./\% & Sigma/\% & RSD $/ \%$ \\
\hline $\mathrm{Si}$ & K12 & 0.001 & 0.001 & 100 \\
$\mathrm{~S}$ & $\mathrm{~K} 12$ & 0.6 & 0.005 & 0.8 \\
$\mathrm{Ca}$ & $\mathrm{K} 12$ & 28 & 0.019 & 0.1 \\
$\mathrm{Ti}$ & $\mathrm{K} 12$ & 0.007 & 0.001 & 8.7 \\
$\mathrm{Fe}$ & $\mathrm{K} 12$ & 0.55 & 0.001 & 0.2 \\
$\mathrm{Cu}$ & $\mathrm{K} 12$ & 0.01 & 0.000 & 2.0 \\
$\mathrm{Zn}$ & $\mathrm{K} 12$ & 0.009 & 0.000 & 2.6 \\
$\mathrm{As}$ & $\mathrm{K} 12$ & 1.6 & 0.002 & 0.1 \\
$\mathrm{Sr}$ & $\mathrm{K} 12$ & 0.3 & 0.000 & 0.2 \\
$\mathrm{~Pb}$ & $\mathrm{~L} 1$ & 0.009 & 0.000 & 3.4 \\
\hline
\end{tabular}

Conc. is the calibrated concentration of the element in weight \%; Sigma is one standard deviation; and RSD is the relative standard deviation expressed in $\%$. The results should be interpreted with some caution because the DCCR calibration is performed with the NIST SRM 610 whose matrix is different from that of the sample. Besides the listed elements $\mathrm{Cl}$ was detected as well, which, however, cannot be properly calibrated

Table 6 DCCR calibrated results of the energy dispersive $X$-ray spectrum of a point analysis AIN 1060 of the white paint

\begin{tabular}{lllll}
\hline Element & Line & Conc./\% & Sigma/\% & RSD $/ \%$ \\
\hline Ca & K12 & 19.4 & 0.013 & 0.1 \\
Sr & K12 & 0.46 & 0.001 & 0.2
\end{tabular}

Conc. is the calibrated concentration of the element in weight \%; Sigma is one standard deviation; and RSD is the relative standard deviation expressed in \%. The DCCR calibration was performed with the BAM RS3, which has a matrix very similar to that of the sample

to have been achieved by mixing the pigments before application. Thus, the slightly blue-tinted green on ÆIN 1048 appears to be applied as a mixture of atacamite and a small amount Egyptian blue. Another example is the mixture of calcite with traces of gypsum/anhydrite and orpiment used for the shaft on ÆIN 1060. Furthermore, the painted decorations display superposing of paint layers which could be interpreted as intentional colour mixing as well. A possible example of layered colour mixing could be the red paint layer applied on top of the yellow paint layer on ÆIN 1058. Both kinds of colour mixing are known from other Egyptian examples [4].

\section{Pigments}

The most dominant pigments of their respective colours in ancient Egyptian painting, Egyptian blue and red ochre, are expected finds. Atacamite has also been attested in several other ancient Egyptian contexts including wall decorations [2]. The small amount of Sn detected in the green paint layer on ÆIN 1059 indicates that bronze rather than copper was used for the manufacture of the atacamite. This is in concordance with other studies of copper-based green and blue pigments from ancient Egypt [9, 66, 67]. As mentioned, the identification of atacamite has been disputed and the suggestion made that the green copper chloride compounds could originate from the degradation of $\mathrm{Cu}$ bearing, natural or synthetic phases rather than pigments in their own right. Indeed, the formation of atacamite from the degradation of Egyptian blue and malachite is well documented. Assessing the remaining decoration on the fragments from the Palace of Apries, several factors are attesting against the hypothesis of the degradation of Egyptian blue: (1) all areas painted with Egyptian blue are well-preserved; (2) degradation products in relation to these areas appear greyish rather than green; (3) the blue- and green-painted areas are clearly distinguishable; (4) the figurative elements are rendered in appropriate tonalities; and (5) the low amounts of $\mathrm{Si}$ is too low to match the hypothesis of degradation of Egyptian blue. This last point is also relevant in rejecting the hypothesis of the degradation of Egyptian green or the formation of atacamite during the manufacturing process of Egyptian blue and Egyptian green as suggested by Schiegl et al. [23].

However, none of these points can discard the degradation of copper carbonate such as malachite or azurite as the origin of the formation of atacamite. Even if these two carbonates have a different molecular structure [68] their degradation process leading to the formation of atacamite is similar. As mentioned before, the degradation of azurite into malachite can occur in humid and alkaline conditions. However, azurite seems to have been very rarely used in ancient Egypt and, as it will be discussed below, the $\mathrm{pH}$ condition of the pigments is more likely acidic. Therefore, the present investigation is focusing on the hypothesis of a direct degradation of copper carbonate into copper chloride rather than on a possible first step implying the degradation of azurite into malachite.

The identification of calcium oxalate in the FTIR spectrum of the sample ÆIN 1060 suggests the presence of oxalic acid $\left(\mathrm{H}_{2} \mathrm{C}_{2} \mathrm{O}_{4}\right)$ probably produced by biodegrading organism such as fungi, lichen or bacteria, or by the oxidation of the original binding media [69]. The oxalic acid could also originate from the degradation of a modern organic material used as surface treatment such as wax [70]. It has been noted that calcite and gypsum are very reactive in the presence of oxalic acid even in low concentration, leading to the formation of calcium oxalate. Therefore, oxalic acid in sample ÆIN 1060 would have first consumed the calcium-rich minerals and formed calcium oxalate before attacking the other pigments [70]. Copper carbonates are less sensitive to oxalic acid than calcite and gypsum, but they are soluble 


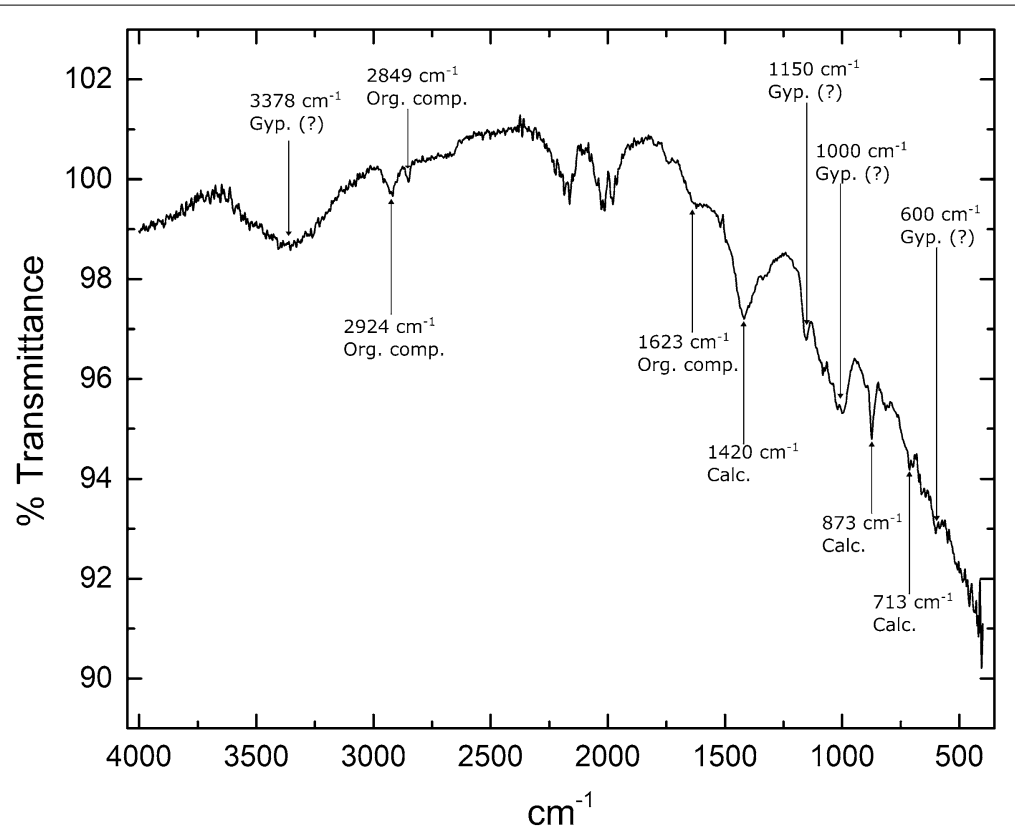

Fig. 15 FTIR spectrum of a small sample of white paint from ÆIN 1060. The characteristic lines of calcite are seen. Also the lines of an organic phase. Tentatively marked are some minor lines of gypsum. However, some of the lines usually associated with gypsum are missing in the spectrum

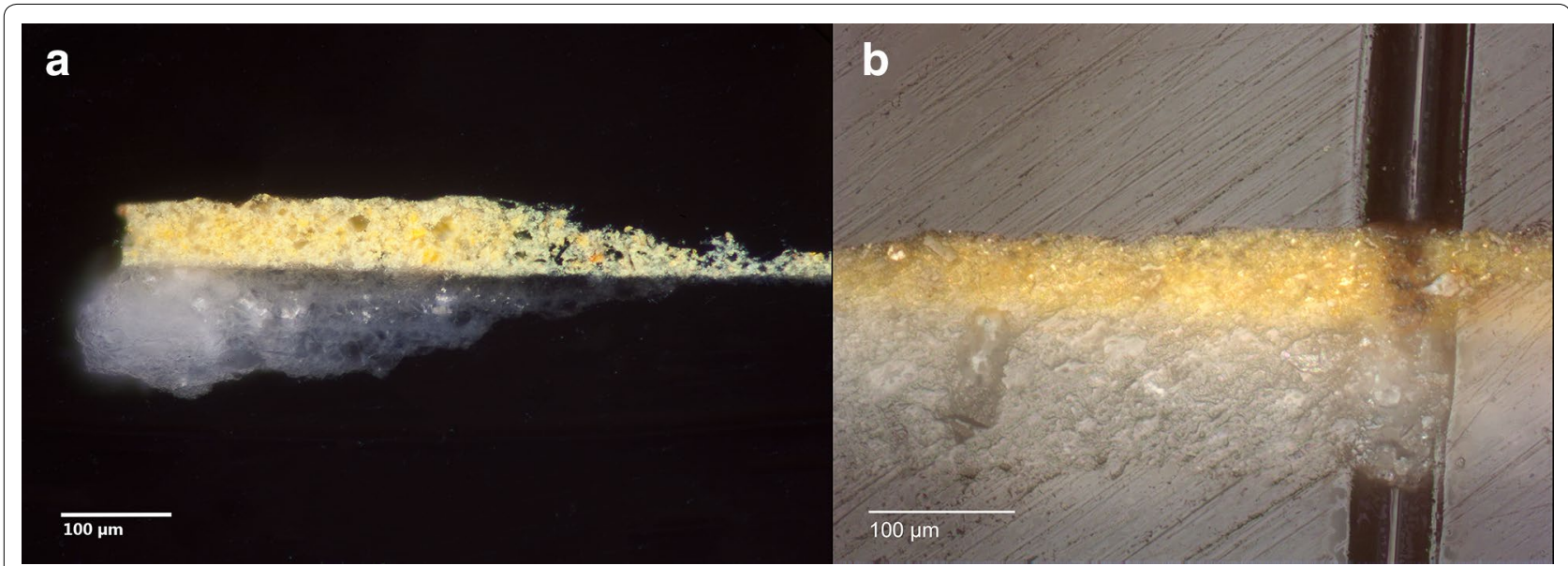

Fig. 16 Optical photos of cross-sections of the yellow paint layer and white ground on ÆIN 1059. a Optical microscope image of ÆIN 1059_1a; b optical image of ÆIN 1059_1b as viewed through the optics of the laser ablator unit after the trace has been ablated

in acidic solution [69]. Assuming a degradation of the original copper carbonate minerals by oxalic acid, $\mathrm{Cu}^{2+}$ ions would be released. When no other anions are available, the $\mathrm{Cu}^{2+}$ ions are combining with the oxalic acid to form copper oxalate (corresponding to the natural mineral moolooite: $\mathrm{CuC}_{2} \mathrm{O}_{4} \cdot \mathrm{nH}_{2} \mathrm{O}$ ). When $\mathrm{Cl}^{-}$ions are presents, they can also react with $\mathrm{Cu}^{2+}$ and precipitates into copper chloride. If gypsum have been consumed by oxalic acid, $\mathrm{SO}_{4}{ }^{-}$ions would also combine with $\mathrm{Cu}^{2+}$ and form copper sulphate $\left(\mathrm{CuSO}_{4} \cdot \mathrm{yCu}(\mathrm{OH})_{2} \cdot \mathrm{zH}_{2} \mathrm{O}\right)$. Among recent publications relating to the degradation process of copper carbonates into copper chloride, it is shown that: 1) the analyses usually displayed a strong signal (FTIR, RAMAN, XRD) belonging to the original copper carbonate minerals used in the pigment layer, proving that the degradation is only partial [18, 26, 27, 29, 30, 71]; (2) when the original copper carbonates are dissolved by oxalic acid, copper oxalate has been detected [26, 70]; (3) when gypsum is first dissolved by oxalic acid, copper sulphate has also been detected [30, 71]. The FTIR 


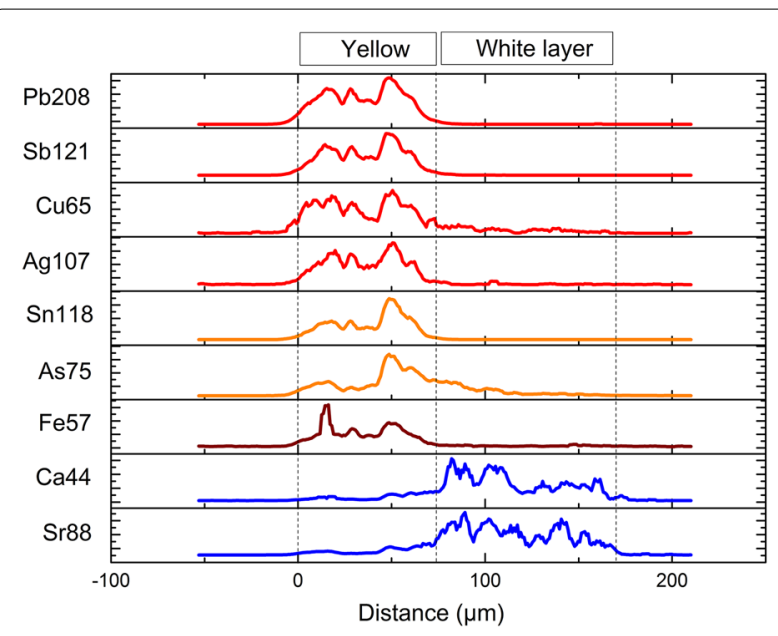

Fig. 17 Results of the LA-ICP-MS on cross-section AIN 1059_1b (KLR-11050). The count rate of each isotope has been normalized to the average of the entire trace. The position of the layers, yellow paint and white ground, are indicated at the top of the plot. The isotopes have been ordered and colour coded according to their co-variance

Table 7 Semi-quantitative concentrations of the average composition of the yellow paint layer in AEIN 1059

\begin{tabular}{lclll}
\hline Element & Yellow layer & $\begin{array}{l}\mathrm{As}_{\mathbf{2}} \mathbf{S}_{\mathbf{3}} \\
\text { orpiment }\end{array}$ & $\begin{array}{l}\mathrm{Pb}_{\mathbf{2}} \mathrm{SnO}_{\mathbf{4}} \\
\text { lead-tin } \\
\text { yellow }\end{array}$ & $\begin{array}{l}\mathrm{Pb}_{\mathbf{2}} \mathrm{Sb}_{\mathbf{2}} \mathbf{O}_{\mathbf{7}} \\
\text { lead- } \\
\text { antimonate } \\
\text { yellow }\end{array}$ \\
\hline $\mathrm{Mg}$ & 0.21 & 0.95 & 1.4 & 9.9 \\
$\mathrm{Si}$ & 3.90 & & & \\
$\mathrm{~S}$ & 0.79 & 0.37 & & \\
$\mathrm{~K}$ & 0.27 & & & \\
$\mathrm{Ca}$ & 8.99 & & & \\
$\mathrm{Ti}$ & 0.06 & & & \\
$\mathrm{Fe}$ & 0.97 & & & \\
$\mathrm{As}$ & 0.58 & 0.58 & & \\
$\mathrm{Sr}$ & 0.15 & & 0.28 & \\
$\mathrm{Sn}$ & 0.28 & & & \\
$\mathrm{Sb}$ & 3.12 & & 0.97 & 5.30 \\
$\mathrm{~Pb}$ & 16.2 & & & \\
\hline
\end{tabular}

Semi-quantitative concentrations of the average composition of the yellow paint layer derived from LA-ICP-MS using an interpolation between the count rates of a $1 \mathrm{ppb}$ multi-element standard (ICP multielement standard solution XXI for MS, by Accustandard), and using the average count rate of Ca 44 over the white ground layer assuming the $\mathrm{Ca}$ concentration was $40 \mathrm{wt} \%$ here corresponding to pure calcite

Using this assumption, the $\mathrm{S}$ and $\mathrm{Sr}$ concentrations of the white ground layer were found to be 0.8 and $1.6 \mathrm{wt} \%$, respectively. All concentrations are in weight percent. The RSD uncertainties are probably not better than c. $20 \%$

spectrum of ÆIN 1060 displayed neither copper oxalate nor copper sulphate. Furthermore, the detection of malachite is uncertain and even if the low intensity peaks can be referred to this mineral phase, the signal is still very weak. Therefore, our results are not pointing towards the degradation of copper carbonates.

Assuming for a moment that the hypothesis of the presence of an original copper chlorine-based pigment is correct, oxalic acid would have attacked the calciumrich phases (calcite or gypsum) but the quantity was not enough to degrade the copper chlorines. However, it is unclear if a massive load of $\mathrm{Cl}^{-}$ions or the long timescale in which the reaction could have occurred could produce the observed result after degradation of copper carbonates. According to these facts, it seems most likely that the atacamite found was an original pigment, but the possibility of the degradation of copper carbonates cannot be entirely dismissed.

Interestingly, the condition of the green paint layers differs significantly. There appears to be a correlation between the presence of yellow-painted areas and the forming of a brown-black crust on the green-painted ones (ÆIN 1059 and 1060). Indeed, orpiment is known to be incompatible with sulphur-sensitive compounds including many $\mathrm{Pb}$ - and $\mathrm{Cu}$-based pigments. When decomposing, orpiment releases sulphur which can react with the $\mathrm{Pb}$ and $\mathrm{Cu}$, forming dark lead and copper sulphides [65, 72]. Egyptian blue, which is a very stable pigment with a relatively low concentration of $\mathrm{Cu}$, appears much less affected by the presence of orpiment (ÆIN 1059). Interestingly, the Pb-based compounds present in the yellow paint layer appear unaffected by the presence of sulphur. Indeed, lead-antimonate yellow is a very stable pigment which is reported to be compatible with all historical pigments [73]. Lead-tin yellow is also quite stable and is unlikely to react with other pigments and airborne impurities unless dispersed in a pure aqueous medium such as gum Arabic [74].

\section{Yellow pigments}

The yellow paint layers contain a puzzling combination of constituents. The identification of orpiment is consistent with our current knowledge of ancient Egyptian painting: the pigment has been identified in several ancient Egyptian contexts from the 12th Dynasty onwards including a 26th-Dynasty coffin [38]. It would appear that pure orpiment was reserved for the rendering of golden details on sarcophagi and papyri whereas mixtures of orpiment and yellow ochre were used for larger surfaces in wall paintings [4]. The yellow pigment mixture identified in yellowpainted areas on the fragments examined might reflect a similar practice.

In addition to orpiment, $\mathrm{Pb}, \mathrm{Sb}$, and $\mathrm{Sn}$ have been identified in the yellow paint layers on ÆIN 1058, 1059, and 1060. For ÆIN 1059 and ÆIN 1060, detailed analyses 


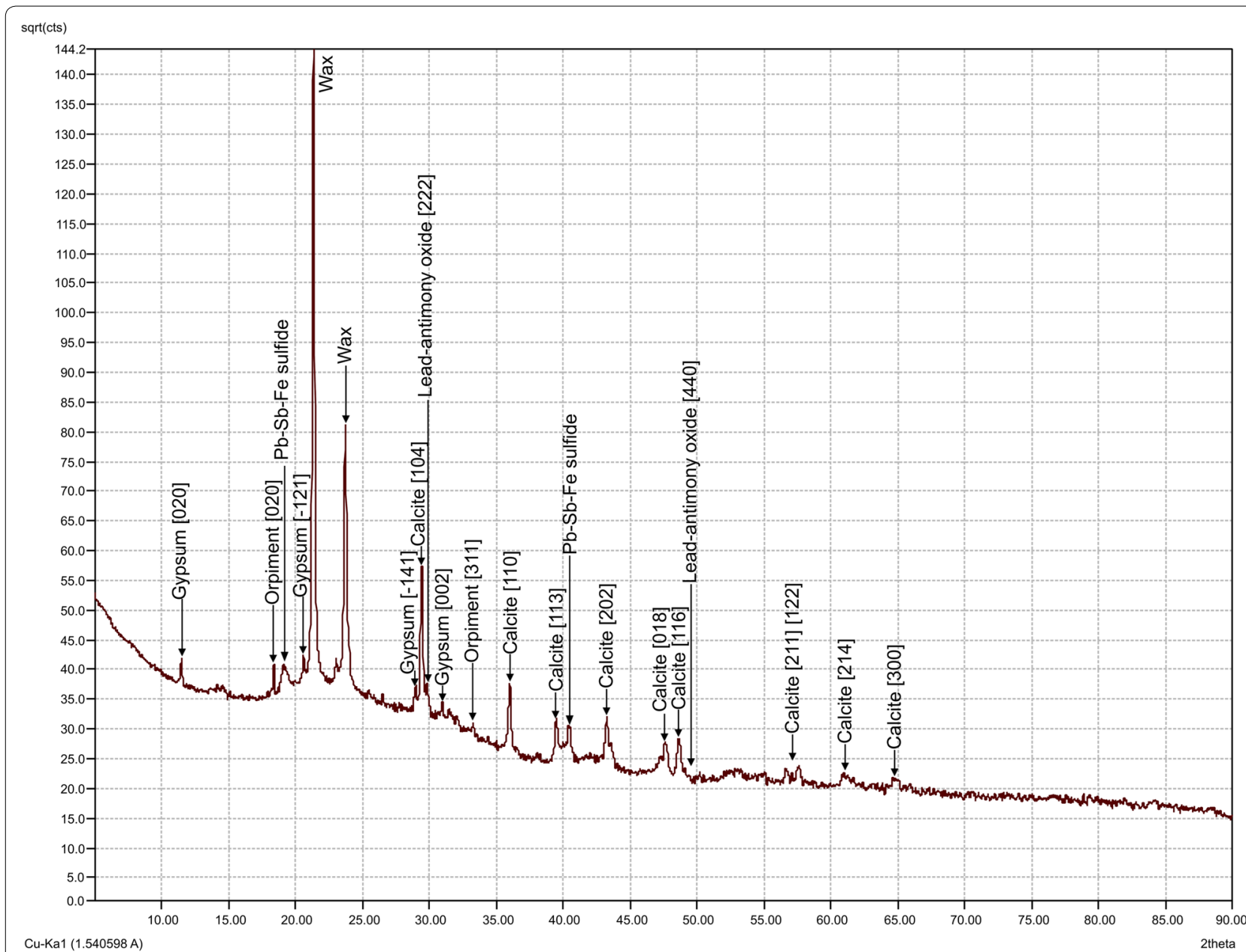

Fig. $18 \mu$-XRPD pattern of the sample of ÆIN 1060 (KLR-12084). Each peak is labelled with the corresponding mineralogical phase and the Miller index

have been conducted with LA-ICP-MS and $\mu$-XRPD. The most likely identification is a mixture of lead-tin yellow $\left(\mathrm{Pb}_{2} \mathrm{SnO}_{4}\right.$, c. $\left.9.9 \mathrm{wt} \%\right)$, lead-antimonate yellow $\left(\mathrm{Pb}_{2} \mathrm{Sb}_{2} \mathrm{O}_{7}\right.$, c. $\left.1.4 \mathrm{wt} \%\right)$ with traces of $\mathrm{Ag}$ and $\mathrm{Cu}$, and orpiment $\left(\mathrm{As}_{2} \mathrm{~S}_{3}\right.$, c. $\left.0.95 \mathrm{wt} \%\right)$. The fact that neither of the lead oxides is known to have been used as a pigment in Antiquity could suggest modern intervention. Indeed, lead-antimonate yellow has been identified on eighteenth century repairs on a coffin from the late 22nd to early 25th Dynasty [75]. However, several lines of arguments make modern intervention unlikely.

Firstly, examining the paint layers and the cross-sections representing them, there is no reason to suspect repainting. If repainted, the secondary application should be easily distinguishable from the original one. The LAICP-MS analysis confirms that the yellow paint layer (ÆIN 1059) is a somewhat heterogeneous pigment mixture. In fact, the concentrations of the more exotic elements are highest towards the bottom of the paint layer examined. Thus, all of the pigments identified were clearly added as a mixture. It should also be noted that the large, pale inclusions of variable sizes and shapes seen in the cross-sections are not in congruence with pigments and paints of the late eighteenth or nineteenth century, which were of a much more heterogeneous composition.

Secondly, since the fragments examined were acquired directly from the excavation there would have been no occasion to touch up the paint layers in order to accommodate the taste of potential buyers. According to the conservation records at the Ny Carlsberg Glyptotek, the fragments have not received any treatment since their arrival. It is true that Petrie often applied wax to the surface of objects from his excavations [76]. Indeed, paraffin appears to have been applied to part of the decoration on ÆIN 1045 [1]. Although this is clearly an act of modern intervention, it is very important to distinguish between a conservation treatment carried out in order to preserve 
Table 8 Summary of the results of the analyses

\begin{tabular}{lll}
\hline Inv. no. & Colour & Pigments \\
\hline EIN 1048 & White & Gypsum and possibly calcium carbonate \\
& Blue & Egyptian blue \\
& Green & Atacamite \\
EIN 1058 & White & Mostly calcium carbonate with traces of \\
& & gypsum \\
& Green & Atacamite \\
EIN 1059 & Yellow & Lead-based component and orpiment \\
& Blue & Calcite \\
& Green & Egyptian blue \\
& Red & Atacamite \\
& Yellow & Haematite \\
& & Orpiment, lead-tin yellow, lead-antimonate \\
& White & yellow \\
& Green & Calcite with gypsum \\
EIN 1060 & Atacamite \\
& Yellow & Calcite with orpiment \\
& & Orpiment, lead-tin yellow, lead-antimonate \\
& & yellow \\
& &
\end{tabular}

what remains and restoration performed in order to improve the appearance of it. Whereas the first appealed to Petrie, the latter surely did not.

Thirdly, neither lead-tin yellow nor lead-antimonate yellow appears to have been readily available at the beginning of the twentieth century. In fact, lead-tin yellow has only been identified in European paintings from c. AD 1300 to 1750 and was only rediscovered three decades after the acquisition of the painted fragments $[8,74]$. Lead-antimonate yellow as well as similar ternary oxides of lead, tin, and antimony $\left(\mathrm{Pb}_{2} \mathrm{SnSbO}_{6.5}\right)$ have been in use since the early sixteenth century. Both antimony-based yellows were gradually replaced by lead chromate and cadmium sulphide pigments in the nineteenth century. During this transitional period, the lead-antimonate yellows were often adulterated with the pigments which would eventually take their place $[8,73]$. Thus, it cannot be ruled out that it was possible to obtain unadulterated lead-antimonate yellow and lead-tin-antimonate yellow in 1909. Summing up, the notion of Petrie partially repainting the decoration appears groundless and out of character. Furthermore, obtaining the pigments in question at the beginning of the twentieth century appears to have been quite difficult. More importantly, the choice of these pigments seems completely unmotivated. It simply defies logic that Petrie should have made any kind of effort to obtain historically incorrect pigments.

When assessing the possibility of an ancient origin, lead-antimonate yellow, the dominant pigment in the mixture identified, is the obvious starting-point.
Interestingly, lead-antimonate yellow was used as a colourant and opacifier in ancient Egyptian glass and faience production from the 18th Dynasty onwards [73, 77, 78]. However, the fact that lead-antimonate yellow has been identified in the glass does not necessarily mean that it was added to the melt in this form. For example, Roman versions appear to have been produced by adding e.g. lead-antimony-silica mixtures [79]. When produced from a silica mixture, the lead-antimony oxides form in the melt and are thus not accessible in pigment form. However, a replication study by Molina et al. [80] concludes that ancient Egyptian lead-antimonate glass was produced by adding an actual lead-antimonate pigment to raw colourless glass. This pigment would have been made by firing a mixture of lead and antimony oxides [80] which is in congruence with the much later European recipes for lead-antimonate-yellow pigments for painting $[8,73]$. Since the glass specimens examined in the referenced as well as other studies are from the New Kingdom [81-83], all of the conclusions drawn may not apply to glass production in the 26th Dynasty. Thus, lead-antimonate yellow glass from the reign of Apries may contain $\mathrm{Sn}$ even though examined specimens from the New Kingdom do not [77].

In contrast to lead-antimonate yellow, lead-tin yellow has not hitherto been attested in the archaeological record from ancient Egypt. Tin-based opacifiers appear to have been introduced during the Ptolemaic Period, c. 300 years after the palace was decorated [77]. As mentioned, Sn identified in copper-based glass, faience, and pigments from ancient Egypt indicates that bronze rather than copper was used for the production suggesting recycling of materials $[9,67]$. Judging from the material published so far, lead, lead alloys, and tin alloys were quite common in ancient Egypt, whereas tin and leadtin alloys were rare [84]. Considering the cost of metal, it is likely that lead and lead-tin alloys were recycled as well. The use of a, possibly recycled, lead-tin alloy could explain the presence of $\mathrm{Sn}$ in the pigment mixture. Given the seeming rarity of lead-tin alloys [84], it is worth considering the possibility of a natural tin-containing lead compound. It is possible that the lead compound used was sourced from a locality where it occurs together with tin-bearing minerals. Ancient Egyptian glass contains small amounts of Fe and $\mathrm{Zn}$ whereas Roman glass, for instance, contains small amounts of $\mathrm{Fe}$ and Sn. The compositional differences indicate that the lead was sourced from different localities [81]. In Egypt lead was extracted from cerrusite $\left(\mathrm{PbCO}_{3}\right)$ and galena $(\mathrm{PbS})$ ores [84]. The latter often occur with sphalerite $(\mathrm{Zn}, \mathrm{Fe}) \mathrm{S}$ [8] which seems a probable source of the Fe and $\mathrm{Zn}$ generally detected in glass from ancient Egypt and in the yellow paint layers examined in this study. It is possible 
that $\mathrm{Sn}$ was included in the lead compound in a similar manner via one of the tin-bearing minerals associated with galena. Similar scenarios pertain to the antimony compound.

Interestingly, the excess of lead identified in this study (cf. Table 7) is concordant with the composition of leadantimonate-yellow glass from the New Kingdom [80]. It is generally argued that excess lead facilitates the initial formation of lead antimonate, the mixing of the pigment into the colourless glass as well as the subsequent stability of the lead antimonate within the glass $[79,83]$. Thus, the excess of lead supports an origin in ancient Egyptian glass making. In sum, it appears that a tin-containing lead-antimonate pigment was available in Egypt in the 26th Dynasty. Considering that both lead-tin yellow and lead-antimonate yellow, when (re)invented in the fifteenth century, were first used in glass production from whence it found its way to the painters' palettes [73, $74]$, an analogue scenario for lead-antimonate yellow in ancient Egypt seems quite feasible.

Apart from the addition of white pigments, mixtures of three pigments are generally associated with degradation products or otherwise unintended additions. The few examples of mixtures containing three colourful pigments all pertain to papyri [4]. As mentioned, low concentrations of Fe detected in the yellow paint layers could indicate the presence of ochre. However, ochre was not detected in the $\mu$-PXRD pattern. Ochre could also be associated with surface dirt or impurities in the other components of the paint layer. Published examples of pigment mixtures suggest a two-component approach. Given our knowledge of ancient Egyptian pigment mixtures, Fe was probably not introduced intentionally. It would appear that the yellow pigment mixture was intended as a mixture of lead-antimonate yellow (containing lead-tin yellow) and orpiment. Based on the semi-quantitative concentrations presented in Table 7, the lead-antimonate yellow pigment contains c. $14 \%$ lead-tin yellow whereas the pigment mixture contains $\mathrm{c}$. $8.4 \%$ orpiment.

\section{Conclusion}

This study gives an account of the inorganic pigments found in the polychromy of the painted architectural fragments from the Palace of Apries in Memphis, Egypt (26th Dynasty, c. 589-568 BCE). The palette identified includes gypsum, calcite, Egyptian blue, haematite, lead-antimonate yellow, lead-tin yellow, orpiment, and probably atacamite. Most of these pigments are paralleled by known examples of ancient Egyptian painting. However, lead-antimonate yellow and leadtin yellow constituting the greater part of the pigment mixture used for the yellow-painted areas have not hitherto been identified in ancient painting. It appears unlikely that the paint layers have been applied since the excavation in 1909.

Lead-antimonate yellow is known from Egyptian glass production from the 18th Dynasty onwards. Indeed, the composition of the pigment identified in this study resembles the reported composition of the lead-antimonate-yellow pigment used for glass production in ancient Egypt. Thus, the small amounts of $\mathrm{Fe}$ and $\mathrm{Zn}$ contained in the pigment used for glass production could account for the small amounts of $\mathrm{Fe}$ and $\mathrm{Zn}$ detected in the paint layer. Likewise, the excess of lead, probably intentionally added to the pigment for glass production, could account for the excess of lead detected in the pigment. This would also serve to emphasise that the pigment used for the painted decoration was produced using a recipe for lead-antimonate-yellow glass. Unlike lead-antimonate yellow, lead-tin yellow has not previously been attested in ancient Egyptian glass. Tin oxide is known from Egyptian glass production, but no $\mathrm{Sn}$ has been identified in lead-antimonate-yellow glass thus far. However, given the 500 years between the glass samples thus far analysed and the painted decoration examined here, it is quite possible that the composition of the pigment might have changed slightly. At present, we can only speculate as to how Sn was included in the pigmentmost probable Sn was included in the firing of a lead and an antimony compound producing a pigment containing lead-antimonate yellow as well as lead-tin yellow.

Fe detected in the paint layer could be present in the form of surface dirt, impurities in the other components. However, considering that ancient Egyptian colour mixing is traditionally a two-component approach, Fe was probably not introduced to the pigment mixture intentionally. Thus, the yellow pigment mixture appears to consist of lead-antimonate yellow containing lead-tin yellow (c. 1/7) mixed with orpiment (c. 1/12).

\footnotetext{
Abbreviations

CHART: Cultural Heritage and Archaeometric Research Team at University of Southern Denmark; DCCR: Direct Calibration from Count Rates; FTIR: Fourier transform infrared spectrometry; GC-MS: gas chromatography mass spectrometry; LA-ICP-MS: laser ablation inductively coupled plasma mass spectrometry; $\mu$-XRF: micro-X-ray fluorescence spectroscopy; $\mu$-XRPD: micro-X-ray powder diffraction; NCG: Ny Carlsberg Glyptotek; UVF: ultraviolet fluorescence; VIL: visible-induced luminescence.

\section{Acknowledgements}

We are very grateful to the Carlsberg Foundation for generously funding the research project Transmission and Transformation. Ancient Polychromy in an Architectural Context, of which this study forms a part. We are also indebted to the Ny Carlsberg Glyptotek for housing the project and kindly granting permission to analyse the artefacts included in this study. In this context we are grateful to Tine Bagh for assisting with the fragments. We would also like
} 
to thank Maria Louise Sargent and Rikke Hoberg Therkildsen for conducting the greater part of the analytical photography included in this study. We are also grateful to Lilian Skytte, Pia Klingenberg Haussmann, Marina Kodic, and Frederik Wendelboe for assistance in the laboratory at CHART. Thanks are also due to Jan Stubbe Østergaard for initiating this work. Lastly, we would like to express our appreciation to the five reviewers for their thorough assessment of our article.

\section{Authors' contributions}

$K L R$, TD, and SBH performed various parts of the analyses. SBH, TD, CB, and KLR drafted the manuscript. All authors read and approved the final manuscript.

\section{Funding}

The project was supported by the Carlsberg Foundation via the project Transmission and Transformation. Ancient Polychromy in an Architectural Context.

\section{Availability of data and materials}

Further detailed data can be obtained from the authors upon request.

\section{Ethics approval and consent to participate}

Not applicable.

\section{Competing interests}

The authors declare that they have no competing interests.

\section{Author details}

${ }^{1}$ Ny Carlsberg Glyptotek, Copenhagen, Denmark. ${ }^{2}$ CHART, Institute of Physics, Chemistry and Pharmacy, University of Southern Denmark, Odense, Denmark.

Received: 8 March 2019 Accepted: 6 July 2019

Published online: 19 July 2019

\section{References}

1. Brøns C, Rasmussen KL, Di Crescenzo M, Stacey R, Lluveras-Tenorio A. Painting the Palace of Apries I: ancient binding media and coatings of the reliefs from the Palace of Apries, Lower Egypt. Heritage Sci. 2018. https:// doi.org/10.1186/s40494-018-0170-9.

2. El Goresy A, Jaksch H, Razek M, Weiner K. Ancient pigments in wall paintings of Egyptian tombs and temples: an archaeometric project. Heidelberg: Max Planck Institut für Kernphysik; 1986.

3. Blom-Böer I. Zusammensetzung altägyptischer Farbpigmente und ihre Herkunftslagerstätten in Zeit und Raum. Oudheidkundige mededelingen uit het Rijksmuseum van Oudheden te Leiden. 1994;74:55-107.

4. Lee L, Quirke S. Painting materials. In: Nicholson PT, Shaw I, editors. Ancient Egyptian materials and technology. Cambridge: Cambridge University Press; 2000. p. 104-20.

5. Davies WV, editor. Colour and painting in ancient Egypt. London: The British Museum Press; 2001.

6. Scott DA. A review of ancient Egyptian pigments and cosmetics. Stud Conserv. 2016;61(4):185-202. https://doi.org/10.1179/2047058414 Y.0000000162.

7. Heywood A. The use of huntite as a white pigment in ancient Egypt. In: Davies WV, editor. Colour and painting in ancient Egypt. London: The British Museum Press; 2001. p. 5-9.

8. Eastaugh N, Walsh V, Chaplin T, Siddall R. The pigment compendium: a dictionary of historical pigments. Oxford: Elsevier Butterworth-Heinemann; 2004.

9. Hatton GD, Shortland J, Tite MS. The production technology of Egyptian blue and green frits from second millennium BC Egypt and Mesopotamia. JAS. 2008;35(6):1591-604. https://doi.org/10.1016/j.jas.2007.11.008.

10. Skovmøller A, Brøns C, Sargent ML. Egyptian blue. Modern mythsancient realities. JRA. 2016;29:371-87.

11. Heywood A. Evidence for the use of azurite and natural ultramarine pigments in ancient Egypt. Metrop Museum Stud Art Sculpt Technol. 2010;1:73-81.

12. Hedegaard SB, Brøns C. New research from Ny Carlsberg Glyptotek: pigments in ancient Palmyra. Palmyrene Studies (forthcoming).

13. Delamare F. Blue pigments: 5000 years of art and industry. London: Archetype Publ; 2013.
14. Riederer J. Recently identified Egyptian pigments: research notes and application reports. Archaeometry. 1974;16(1):102-9. https://doi. org/10.1111/j.1475-4754.1974.tb01098.x.

15. Pagès-Camagna S, Guichard H. Egyptian colours and pigments in French collections: 30 years of physicochemical analyses on 300 objects. In: Rozeik C, Dawson J, Wright M, editors. Decorated surfaces on ancient Egyptian objects: technology, deterioration and conservation. Cambridge: Fitzwilliam Museum, University of Cambridge; 2010. p. 142-7.

16. Weatherhead F, Buckley A. Artists' pigments from Amarna. In: Kemp BJ, editor. Amarna Reports V. London: EES; 1989. p. 202-39.

17. David AR, Edwards HGM, Farwel DW, DeFaria DLA. Raman spectroscopic analysis of ancient Egyptian pigments. Archaeometry. 2001;43(1):461-73. https://doi.org/10.1111/1475-4754.00029.

18. Scott DA. Ancient Egyptian pigments: the examination of some coffins from the San Diego Museum of Man. MRS. 2014;35:390-6. https://doi. org/10.1080/00393630.2017.1331549.

19. Siddall R. Mineral pigments in archaeology: their analysis and the range of available materials. Minerals. 2018. https://doi.org/10.3390/min80 50201.

20. Cavallo G. Alteration of azurite into paratacamite at the St. Alessandro church (Lasnigo, Italy). Conservar património. 2009;9:5-11. https://doi. org/10.14568/cp9_2.

21. Dei L, Ahle A, Baglioni P, Dini D, Ferroni E. Green degradation products of azurite in wall paintings: identification and conservation treatment. Stud Conserv. 1998;43(2):80-8. https://doi.org/10.1179/sic.1998.43.2.80.

22. Schiegl S, Weiner KL, El Goresy A. The diversity of newly discovered deterioration patterns in ancient Egyptian pigments: consequences to entirely new restoration strategies and to Egyptological colour symbolism. In: Materials research society symposium proceedings, vol. 267. 1992, p. 831-58.

23. Schiegl S, Weiner KL, El Goresy A. Discovery of copper chloride cancer in ancient Egyptian polychromic wall paintings and faience: a developing archaeological disaster. Naturwissenschaften. 1989;76:393-400.

24. Gimenez J. Finding hidden chemistry in ancient Egyptian artifacts: pigment degradation taught in a chemical engineering course. J Chem Educ. 2015;92:456-62. https://doi.org/10.1021/ed500327j.

25. Gimenez J. Egyptian blue and/or atacamite in an ancient Egyptian coffin. Int J Conserv Sci. 2015;6(4):747-9.

26. Lluveras A, Boularand S, Andreotti A, Vendrell-Saz M. Degradation of azurite in mural paintings: distribution of copper carbonate, chlorides and oxalates by SRFTIR. Appl Phys A Mater Sci Process. 2010;99(2):363-75. https://doi.org/10.1007/s00339-010-5673-5.

27. Dominguez-Vidal A, Torre-López MJ, Campos-Suñol MJ, Rubio-Domene R, Ayora-Cañada MJ. Decorated plasterwork in the Alhambra investigated by Raman spectroscopy: comparative field and laboratory study. J Raman Spectrosc. 2014;45(11-12):1006-12. https://doi.org/10.1002/jrs.4439.

28. Coccato A, Moens L, Vandenabeele P. On the stability of mediaeval inorganic pigments: a literature review of the effect of climate, material selection, biological activity, analysis and conservation treatments. Heritage Sci. 2017;5(1):12. https://doi.org/10.1186/s40494-017-0125-6.

29. Vandenabeele P, Lambert K, Matthys S, Schudel W, Bergmans A, Moens L. In situ analysis of mediaeval wall paintings: a challenge for mobile Raman spectroscopy. Anal Bioanal Chem. 2005;383(4):707-12. https://doi org/10.1007/s00216-005-0045-2.

30. Švarcová S, Hradil D, Hradilová J, Kočí E, Bezdička P. Micro-analytical evidence of origin and degradation of copper pigments found in Bohemian Gothic murals. Anal Bioanal Chem. 2009;395(7):2037-50. https://doi. org/10.1007/s00216-009-3144-7.

31. Colinart S. Analysis of inorganic yellow colour in ancient Egyptian painting. In: Davies WV, editor. Colour and painting in ancient Egypt. London: The British Museum Press; 2001. p. 1-4.

32. Helwig K. Iron oxide pigments: natural and synthetic. In: Berrie BH, editor. Artists' pigments: a handbook of their history and characteristics, vol. 4. Washington: National Gallery of Art, Archetype Publ; 2007. p. 39-109.

33. Uda M, Sassa S, Yoshimura S, Kondo J, Nakamura M, Ban Y, Adachi H. Red, yellow and blue pigments from ancient Egyptian palace painted walls. Nucl Instrum Methods Phys Res B. 2000;161(161-163):758-61. https://doi. org/10.1016/S0168-583X(99)00969-6.

34. Pagès-Camagna S, Laval E, Vigears D, Duran A. Non-destructive and in situ analysis of Egyptian wall paintings by X-ray diffraction and X-ray 
fluorescence portable systems. Appl Phys A. 2010;100(3):671-81. https:// doi.org/10.1007/s00339-010-5667-3.

35. Daniels V, Leach B. The occurrence and alteration of realgar on ancient Egyptian papyri. Stud Conserv. 2004;52:73-84. https://doi.org/10.1179/ sic.2004.49.2.73.

36. Evans D., Hamburg D, Mickelson M. A papyrus treatment: bringing the Book of the Dead to life. In: Art conservation training programs conference, April 28-29, 1980. Newark: University of Delaware. 1980. pp. 109-13.

37. Le Fur D. Les pigments dans la peinture égyptienne. In: Pigments et colorants de l'Antiquité et du Moyen Age. International colloquium at CNRS, Paris. 1990. pp. 181-8.

38. Bonizzoni L, Bruni S, Gugliemi V, Milazzo M, Neri O. Field and laboratory multi-technique analysis of pigments and organic painting media from an Egyptian coffin of 26th Dynasty. Archaeometry. 2011;53(6):1212-30. https://doi.org/10.1111/j.1475-4754.2011.00592.x.

39. Gettens RJ, Feller RL, Chase WT. Vermillion and cinnabar. In: Roy A, editor. Artists' pigments: a handbook of their history and characteristics, vol. 2. Washington: National Gallery of Art, Archetype Publ; 1993. p. 159-82 (reprinted 2012)

40. Edwards HGM, Jorge Villar SE, Eremin KA. Raman spectroscopic analysis of pigments from Dynastic Egyptian funerary artefacts. J Raman Spectrosc. 2004;33:786-895. https://doi.org/10.1002/jrs.1193.

41. Middleton A, Humphrey S. Pigments on some Middle Kingdom coffins. In: Davies WV, editor. Colour and painting in ancient Egypt. London: The British Museum Press; 2001. p. 10-6.

42. Petrie WMF. The Palace of Apries (Memphis II). London: School of archaeology in Egypt, University College; 1909.

43. Kaiser W. Die dekorierte Torfassade des spätzeitlichen Palastbezirkes von Memphis. MDAIK. 1987;43:123-54.

44. Bagh T. Finds from W.M.F. Petrie's excavations in Egypt in the Ny Carlsberg Glyptotek. Copenhagen: Ny Carlsberg Glyptotek; 2011.

45. Jørgensen M. Catalogue. Egypt IV. Late Egyptian Sculpture 1080 BC-AD 400. Copenhagen: Ny Carlsberg Glyptotek; 2009.

46. Jørgensen M. Catalogue. Egypt IV. Late Egyptian Sculpture 1080 BC-AD 400. Copenhagen: Ny Carlsberg Glyptotek; 2009: cat. 29.1.

47. Jørgensen M. Catalogue. Egypt IV. Late Egyptian Sculpture 1080 BC-AD 400. Copenhagen: Ny Carlsberg Glyptotek; 2009: cat. 26.2.

48. Jørgensen M. Catalogue. Egypt IV. Late Egyptian Sculpture 1080 BC-AD 400. Copenhagen: Ny Carlsberg Glyptotek; 2009: cat. 25.4.

49. Jørgensen M. Catalogue. Egypt IV. Late Egyptian Sculpture 1080 BC-AD 400. Copenhagen: Ny Carlsberg Glyptotek; 2009: cat. 25.3.

50. Jørgensen M. Catalogue. Egypt IV. Late Egyptian Sculpture 1080 BC-AD 400. Copenhagen: Ny Carlsberg Glyptotek; 2009: cat. 26.1.

51. Dyer J, Verri G, Cupitt J. Multispectral imaging in reflectance and photoinduced luminescence modes: a user manual. London: British Museum; 2013. https://www.britishmuseum.org/pdf/charisma-multispectral-imagi ng-manual-2013.pdf.

52. Sargent ML, Therkildsen RH. The technical investigation of sculptural polychromy at the Ny Carlsberg Glyptotek 2009-2010-an outline. In: Østergaard JS, editor. Tracking colour: the polychromy of Greek and Roman sculpture in the Ny Carlsberg Glyptotek. Preliminary report 2. 2010. pp. 11-26. https://www.trackingcolour.com/assets/d/0/1207//rack ing_Colour_2_final.pdf.

53. Accorsi G, Verri G, Bolognesi M, Armaroli N, Clementi C. The exceptional near-infrared luminescence properties of cuprorivaite (Egyptian blue). Chem Commun. 2009;23:3392-4.

54. Verri G. The application of visible-induced luminescence imaging to the examination of museum objects. In: Pezzati L, Salimbeni R, editors. Optics for art, architecture, and archaeology II, Proceedings of SPIE, vol. 7391. 2009. pp. 739105.1-739105.12. https://doi.org/10.1117/12.827331.

55. Guillong M, Latkoczy C, Seo JH, Günther D, Heinrich CA. Determination of sulfur in fluid inclusions by laser ablation ICP-MS. JAAS. 2008;23(12):15819. https://doi.org/10.1039/b807383j.

56. Frost RL, Martens W, Kloprogge JT, Williams PA. Raman spectroscopy of the basic copper chloride minerals atacamite and paratacamite: implications for the study of copper, brass and bronze objects of archaeological significance. J Raman Spectrosc. 2002;33(10):801-6. https://doi, org/10.1002/jrs.921.

57. Vahur S, Teearu A, Peets P, Joosu L, Leito I. ATR-FT-IR Spectral collection of conservation materials in the extended region of $4000-80 \mathrm{~cm}^{-1}$.
Anal Bioanal Chem. 2016;408(3):3373-9. https://doi.org/10.1007/s0021 6-016-9411-5.

58. Poduska K, Regev L, Berna F, Mintz E, Milevski I, Khalaily H, Weiner S, Boaretto E. Plaster characterization at the PPNB Site of Yiftahel (Israel) including the use of 14C: implications for plaster production, preservation, and dating. Radiocarbon. 2012;54(3-4):887-96. https://doi. org/10.1017/S0033822200047536.

59. Anbalagan G, Mukundakumari S, Sakthi Murugesan K, Gunasekaran S. Infrared, optical absorption, and EPR spectroscopic studies on natural gypsum. Vib Spectrosc. 2009;50(2):226-30. https://doi.org/10.1016/j.vibsp ec.2008.12.004.

60. Papp G, Criddle AJ, Stanley CJ, Kriston L, Nagy G. Parajamesonite revisited: background of the discreditation of an enigmatic mineral species. Swiss J Geosci. 2007;100(3):495-502. https://doi.org/10.1007/s00015-007-1233-1.

61. Švarcová S, Kočí E, Bezdička P, Hradil D, Hradilová J. Evaluation of laboratory powder X-ray micro-diffraction for applications in the fields of cultural heritage and forensic science. Anal Bioanal Chem. 2010;398(2):106176. https://doi.org/10.1007/s00216-010-3980-5.

62. Mahmoud HM, Kantiranis N, Ali M, Stratis J. Characterization of Ancient Egyptian Wall Paintings, the Excavations of Cairo University at Saqqara. Int J Conserv Sci. 2011;2(3):145-54.

63. Mahmoud HHM. A multi-analytical approach for characterizing pigments from the Tomb of Djehutyemhab (TT194), El-Qurna Necropolis, Upper Egypt. Archeometriai Múhely. 2012;9(3):205-14.

64. McCarthy B. Technical analysis of reds and yellows in the Tomb of Suemniwet, Theban Tomb. In: Davies WV, editor. Colour and painting in ancient Egypt. London: The British Museum Press; 2001. p. 17-21.

65. Fitzhugh EW. Orpiment and realgar. In: Fitzhugh EW, editor. Artists' pigments: a handbook of their history and characteristics, vol. 3. Washington: National Gallery of Art, Archetype Publ; 1997. p. 47-79 (reprinted 2012).

66. Sayre EV, Smith RW. Analytical studies of ancient Egyptian glass. In: Cairo solid state conference, Cairo. Oak Ridge, Tenn: Office of Scientific and Technical Information, U.S. Dept. of Energy. 1973. https://link.springer. com/10.1007/978-1-4684-7233-2_4.

67. El Goresy A. Polychromatic wall painting decoration in monuments of Pharaonic Egypt: compositions, chronologies and painting techniques. In: Sherratt S, editor: Proceedings of the first international symposium: the wall painting of Thera. Piraeus: Thera Foundation; 2000. pp. 49-70.

68. Frost RL, Reddy J, Wain D, Martens W. Identification of the rosasite group minerals - an application of near infrared spectroscopy. Spectrochim Acta A Mol Biomol Spectrosc. 2007;66(4-5):1075-81. https://doi. org/10.1016/j.saa.2006.04.043.

69. Zoppi A, Lofrumento C, Mendes NF, Castellucci EM. Metal oxalates in paints: a Raman investigation on the relative reactivities of different pigments to oxalic acid solutions. Anal Bioanal Chem. 2010;397(2):841-9. https://doi.org/10.1007/s00216-010-3583-1.

70. Castro K, Sarmiento A, Martínez-Arkarazo I, Madariaga JM, Fernández LA. Green copper pigments biodegradation in cultural heritage: from malachite to moolooite, thermodynamic modeling, X-ray fluorescence, and Raman evidence. Anal Chem. 2008;80(11):4103-10. https://doi. org/10.1021/ac800255w.

71. Pérez-Alonso M, Castro K, Madariaga JM. Investigation of degradation mechanisms by portable Raman spectroscopy and thermodynamic speciation: the wall painting of Santa María de Lemoniz (Basque Country, North of Spain). Anal Chim Acta. 2006;571(1):121-8. https://doi. org/10.1016/j.aca.2006.04.049.

72. Vermeulen M, Sanyova J, Janssens K, Nuyts G, De Meyer S, De Wael K. The darkening of copper- or lead-based pigments explained by a structural modification of natural orpiment: a spectroscopic and electrochemical study. J Anal At Spectrom. 2017;32(9):1331-41. https://doi.org/10.1039/ C7JA00047B.

73. Wainwright INM, Taylor JM, Harley RD. Lead antimonate yellow. In: Feller $\mathrm{RL}$, editor. Artist's pigments. A handbook of their history and characteristics, vol. 1. Cambridge: Cambridge University Press; 1986. p. 219-54 (reprinted 2012).

74. Kühn H. Lead-tin yellow. In: Roy A, editor. Artists' pigments: a handbook of their history and characteristics, vol. 2. Washington: National Gallery of Art, Archetype Publ; 1993. p. 83-112 (reprinted 2012).

75. Bracci S, Caruso O, Galeotti M, lannaccone R, Magrini D, Picchi D, Pinna D, Porcinai S. Multidisciplinary approach for the study of an Egyptian coffin (late 22nd/early 25th dynasty): combining imaging and spectroscopic 
techniques. Spectrochim Acta A Mol Biomol Spectrosc. 2015;145:511-22. https://doi.org/10.1016/j.saa.2015.02.052.

76. Petrie WMF. Hawara, Biahmu and Arsinoe. London: Field \&Tuer; 1899.

77. Nicholson P, Henderson J. Glass. In: Nicholson PT, Shaw I, editors. Ancient Egyptian materials and technology. Cambridge: Cambridge University Press; 2000. p. 195-224.

78. Nicholson P, Peltenburg E. Egyptian Faience. In: Nicholson PT, Shaw I, editors. Ancient Egyptian materials and technology. Cambridge: Cambridge University Press; 2000. p. 177-94.

79. Freestone IC, Stapleton CP. Composition, technology, and production of coloured glasses from Roman mosaic vessels. In: Bayley J, Freestone I, Jackson C, editors. Glass of the Roman Empire. Oxbow: Oxford; 2015. p. $61-76$.

80. Molina G, Odin GP, Pradell T, Shortland AJ, Tite MS. Production technology and replication of lead antimonate yellow glass from New Kingdom Egypt and the Roman Empire. JAS. 2014;41:171-84. https://doi. org/10.1016/j.jas.2013.07.030.

81. Lahlil S, Cotte M, Biron I, Szlachetko J, Menguy N, Susini J. Synthesizing lead antimonate in ancient and modern opaque glass. JAAS. 2011;26(5):1040-50. https://doi.org/10.1039/COJA00251H.
82. Mass JL, Wypyski MT, Stone RE. Malkata and Lisht glassmaking technologies: towards a specific link between second millennium BC metallurgists, and glassmakers. Archaeometry. 2002;44(1):67-82. https://doi. org/10.1111/1475-4754.00043.

83. Shortland AJ. The use and origin of antimonate colorants in early Egyptian glass. Archaeometry. 2002;44(4):517-31. https://doi. org/10.1111/1475-4754.t01-1-00083.

84. Metals Ogden J. In: Nicholson PT, Shaw I, editors. Ancient Egyptian materials and technology. Cambridge: Cambridge University Press; 2000. p. $148-76$.

\section{Publisher's Note}

Springer Nature remains neutral with regard to jurisdictional claims in published maps and institutional affiliations.

\section{Submit your manuscript to a SpringerOpen ${ }^{\circ}$ journal and benefit from:}

- Convenient online submission

- Rigorous peer review

- Open access: articles freely available online

- High visibility within the field

- Retaining the copyright to your article

Submit your next manuscript at $\boldsymbol{\nabla}$ springeropen.com 